\title{
When and Whom to Join: The Expansion of Ongoing Violent Interstate Conflicts
}

\author{
KYLE A. JOYCE, FATEN GHOSN AND REŞAT BAYER*
}

The opportunity and willingness framework has received much attention in research on interstate conflict expansion. This framework is extended here by examining when and what side third parties join during ongoing conflicts. It is maintained that without examining both timing and side selection, understanding of conflict expansion is limited. The timing and side joined in interstate disputes between 1816 and 2001 are analysed using a competing risks duration model. The findings contribute novel insights into many key debates in conflict research such as balancing versus bandwagoning, as well as alliance reliability and the democratic peace. The results also indicate that relying on statistical models that do not distinguish between which side a third party can join may produce misleading results.

Military conflicts that expand are far deadlier than those that do not. While only 27 per cent of the wars between 1816 and 2007 expanded to include at least one additional state (that is, third party) after the war began; those wars were among the deadliest, accounting for 87 per cent of the fatalities across all of the wars during this time period. Given the extraordinary destruction that conflict expansion augurs, understanding third parties' decisions to join ongoing conflicts is important. More specifically, it is crucial to understand when during a conflict third parties join and what side they join, since these decisions can dramatically affect the conflict's evolution and outcome. For example, the US decision to join the Allied Powers in World War I dramatically influenced the outcome of the war, as did the UK decision to join the conflict that became World War II. More recent conflicts, such as those in Afghanistan, Congo and Iraq, have also expanded to include additional states on one or both sides at different points in time. We argue that in order to explain the expansion of interstate disputes, it is necessary to understand when third parties join and what side they join - otherwise our understanding of conflict expansion will be limited, since our theories and analyses will lack information about key components of the conflict process. Moreover, understanding these decisions will improve our knowledge of the dynamic processes of conflicts more generally.

While extant research has identified several factors that influence third parties' decisions to join ongoing disputes, few studies have examined how these factors influence the timing of third-party joining or how they might differ for joining the initiator of a dispute

* University of California, Davis Department of Political Science; University of Arizona School of Government and Public Policy; and Koç University Department of International Relations (email: rbayer@ku.edu.tr), respectively. Authors' names are in reverse alphabetical order, implying equal authorship. The authors wish to thank D. Scott Bennett, Janet M. Box-Steffensmeier, Amber Boydstun, Vesna Danilovic, Errol Henderson, Jan Leighley, Doug Lemke, Glenn Palmer, Dan Reiter and the anonymous referees and the editor for their comments and suggestions. Cansu Güner, Shaina Western and Sheryl Zaks provided research assistance. Special thanks are offered in memoriam to Stuart A. Bremer. The data used in this article, along with a web appendix containing coding decisions and additional results, are available at $\mathrm{http}: / / \mathrm{psfaculty}$.ucdavis.edu/kjoyce/. There is an online appendix available at http://dx.doi.org/10.1017/S0007123412000506, and data replication may be requested from Bayer. 
compared to joining the target. Most existing research examining the timing of thirdparty joining ignores which side a third party joined, and research that has examined the side of third-party joining has typically ignored the timing of that joining. ${ }^{1}$ In this article we examine how these factors influence both the timing of third-party joining and the side they join during ongoing disputes. ${ }^{2}$

We build on the opportunity and willingness framework, which has received considerable attention in the study of interstate conflict diffusion and in international relations (IR) research more broadly. ${ }^{3}$ Although other perspectives could be used to study third-party intervention, such as bargaining or spatial diffusion models, ${ }^{4}$ the opportunity and willingness framework seems appropriate as a first cut to examine the timing and side of third-party joining during ongoing disputes. ${ }^{5}$ We expand this framework, originally presented in terms of alliances and contiguity, to include several additional factors that influence a third party's opportunity or willingness to join an ongoing dispute.

In addition to extending the opportunity and willingness framework, we build on existing conflict expansion research in two ways. First, we examine the timing of thirdparty joining. Militarized conflict is a dynamic process, and third-party joining has an important effect on the evolution of a conflict. In particular, a third party has the ability to influence the eventual outcome of a dispute by changing the probability that each initial belligerent will win. Additionally, the timing of third-party joining is important because it can influence the length of a dispute. For example, the entry of the United States into World Wars I and II decisively influenced their evolution - in particular their length and final outcome. In World War I, the United States joined after Germany had improved its military position and just prior to Russia's exit. In World War II, the United States joined after France exited and both the UK and the USSR were suffering on the battlefield.

1 Arvid Raknerud and Håvard Hegre, 'The Hazard of War: Reassessing the Evidence for the Democratic Peace', Journal of Peace Research, 34 (1997), 385-404; Randolph M. Siverson and Harvey Starr, The Diffusion of War: A Study of Opportunity and Willingness (Ann Arbor: University of Michigan Press, 1991); Dan Reiter and Allan C. Stam, Democracies at War (Princeton, N.J.: Princeton University Press, 2002); Suzanne Werner and Douglas Lemke, 'Opposites Do Not Attract: The Impact of Domestic Institutions, Power, and Prior Commitments on Alignment Choices', International Studies Quarterly, 41 (1997), 529-46; but see Molly M. Melin and Michael T. Koch, 'Jumping into the Fray: Alliances, Power, Institutions, and the Timing of Conflict Expansion', International Interactions, 36 (2010), 1-27.

${ }^{2}$ We focus on military interventions by third parties and do not consider other forms of intervention (such as economic or diplomatic) or other ways of intervening (such as mediation), although the approach we use here could be extended to those domains as well. Renato Corbetta, 'Determinants of Third Parties' Intervention and Alignment Choices in Ongoing Conflicts, 1946-2001', Foreign Policy Analysis, 6 (2010); Renato Corbetta and William J. Dixon, 'Danger Beyond Dyads: Third-Party Participants in Militarized Interstate Disputes', Conflict Management and Peace Science, 22 (2005), 39-61; Patrick Regan and Aysegul Aydin, 'Diplomacy and Other Forms of Intervention in Civil Wars', Journal of Conflict Resolution, 50 (2006), 736-56; Michael Greig, 'Stepping into the Fray: When Do Mediators Mediate?', American Journal of Political Science, 49 (2005), 249-66.

${ }^{3}$ Corbetta, 'Determinants of Third Parties' Intervention and Alignment Choices'; Siverson and Starr, The Diffusion of War; Werner and Lemke, 'Opposites Do Not Attract'.

${ }^{4}$ Suzanne Werner, 'Deterring Intervention: The Stakes of War and Third-Party Involvement', American Journal of Political Science, 44 (2000), 720-32; Amy Yuen, 'Target Concessions in the Shadow of Intervention', Journal of Conflict Resolution, 53 (2009), 727-44; Beth A. Simmons and Zachary Elkins, 'The Globalization of Liberalization: Policy Diffusion in the International Political Economy', American Political Science Review, 98 (2004), 171-89.

5 Siverson and Starr, The Diffusion of War; Werner and Lemke, 'Opposites Do Not Attract'. 
The importance of timing has been recognized for quite some time in conflict expansion research. For example, Siverson and Starr note: 'There is another related aspect of war diffusion that is of significance... What accounts for the variation in the length of time it took nations to join ongoing wars? ${ }^{6}$ However, very little research examines when and what side third parties join in ongoing disputes. ${ }^{7}$

Secondly, we examine how the factors that purport to explain the timing of third-party joining might differ between joining the initiator of a dispute and joining the target. A third party's decisions about whether to join an ongoing conflict and what side it would join are not independent decisions. For example, after Germany invaded Poland in 1939, it is unlikely that the UK first decided whether to join the conflict and then decided whether it would align with Germany or Poland. The UK decision to join was not independent of its decision about which side to join. Extant conflict expansion research has also differentiated between joining the two sides in a dispute, but most existing research does not examine side selection alongside timing (an exception is Melin and Koch). ${ }^{8}$

Our focus on side selection contributes to the growing body of political science research that focuses on context. ${ }^{9}$ The initiators and targets of disputes provide the context that influences third parties' decisions to join. ${ }^{10}$ Our results show that without incorporating this context, the results obtained from statistical models can be misleading. Additionally, rather than separating third parties' timing and side selection decisions, our empirical analysis models these interdependent decisions using a competing risks event history model.

Our theoretical arguments and empirical findings are directly relevant to several debates in IR: whether states respond to more powerful states by balancing against or bandwagoning with them, whether states fulfill their alliance obligations or not, whether states of the same regime type behave differently towards one another than states of different regime types (by aligning with states that have similar regimes), whether states respond to perceived threats by aligning against rivals, and whether geographically proximate states align with or against neighbours. There is extensive theoretical interest in each of these topics in IR, and conflict research in particular. We attempt to reconcile disparate findings in the conflict expansion literature that speak to these debates.

The article proceeds as follows. First, we discuss the opportunity and willingness framework. Secondly, we present our extensions to this framework and our hypotheses about how each factor influences the time until a third party joins the initiator or the target. Thirdly, we present our research design. Fourthly, we report the results of our analysis, which demonstrate the importance of distinguishing between joining the initiator and joining the target, and show that conflating these choices can lead to incorrect inferences. Finally, we discuss our contributions to the research on conflict expansion and IR more broadly, and point out specific avenues for future research.

${ }^{6}$ Siverson and Starr, The Diffusion of War, p. 2.

7 Melin and Koch examine the timing of joining but focus on different theoretical arguments and use a different research design and statistical approach. Melin and Koch, 'Jumping into the Fray'.

${ }^{8}$ Corbetta, 'Determinants of Third Parties' Intervention and Alignment Choices'; Siverson and Starr, The Diffusion of War; Werner and Lemke, 'Opposites Do Not Attract'; Melin and Koch, 'Jumping into the Fray'.

9 Robert Goodin and Charles Tilly, eds, The Oxford Handbook of Contextual Political Analysis (Oxford: Oxford University Press, 2006).

${ }^{10}$ Gary Goertz, Contexts of International Politics (New York: Cambridge University Press, 1994). 


\section{OPPORTUNITY AND WILLINGNESS FRAMEWORK}

The opportunity and willingness framework, developed by Starr and Most, who built on the research of Boulding as well as Sprout and Sprout, has been extensively used in international and civil conflict research. ${ }^{11}$ For example, it has been used to examine a variety of topics including democratic peace theory and shared rivers and water scarcity. ${ }^{12}$ One of the main approaches to the study of civil wars also uses this approach by focusing on feasibility and motivation. For example, Collier, Hoeffler and Rohner maintain that their 'approach is to find proxies for each of the major perspectives: feasibility, and the two main variants of motivation, greed and grievance'. ${ }^{13}$

Siverson and Starr conceptualize opportunity as the 'degree of interaction' or 'interaction opportunity', meaning that 'some activity must at base be physically, technologically, or intellectually possible. ${ }^{14}$ In essence, 'opportunity consists both of the possibilities that exist in the international system at any point in history (for example, technology, ideology, religion, social inventions such as new forms of government), and how those possibilities are distributed in the system. ${ }^{15}$

While opportunity concerns the possibility of militarized conflict, "willingness deals with the motivations and goals of policy makers, and the decision making processes that lead them to choose the "war" alternative rather than "no war". ${ }^{16}$ Siverson and Starr elaborate on the concept to include 'a decision maker's calculations of advantage and disadvantage, cost and benefit, considered on both conscious and unconscious levels. It is through willingness that decision makers recognize opportunities and then translate those opportunities into alternatives that are weighed in some manner. ${ }^{17}$

Two particularly relevant articles that use the opportunity and willingness framework to examine conflict expansion are Siverson and Starr and Werner and Lemke. ${ }^{18}$ Siverson and Starr used this framework to examine the timing of joining ongoing interstate wars without considering which side is joined. They hypothesized that 'the greater a nation's

${ }^{11}$ Harvey Starr, "'Opportunity" and "Willingness" as Ordering Concepts in the Study of War', International Interactions, 4 (1978), 363-87; Benjamin A. Most and Harvey Starr, Inquiry, Logic and International Politics (Columbia, S.C.: University of South Carolina Press, 1989); Kenneth E. Boulding, Conflict and Defense: A General Theory (New York: Harper \& Row, 1962); Harold Sprout and Margaret Sprout, The Ecological Perspective on Human Affairs (Princeton, N.J.: Princeton University Press, 1965); Harold Sprout and Margaret Sprout, 'Environmental Factors in the Study of International Politics', in James N. Rosenau, ed., International Politics and Foreign Policy (New York: The Free Press, 1969), pp. $60-72$.

${ }^{12}$ Erik Gartzke, 'Kant We All Just Get Along? Opportunity, Willingness, and the Origins of the Democratic Peace', American Journal of Political Science, 42 (1998), 1-27; Kathryn Furlong, Nils Petter Gleditsch and Håvard Hegre, 'Geographic Opportunity and Neomalthusian Willingness: Boundaries, Shared Rivers, and Conflict', International Interactions, 32 (2006), 79-108.

${ }^{13}$ Paul Collier, Anke Hoeffler and Dominic Rohner, 'Beyond Greed and Grievance: Feasibility and Civil War', Oxford Economic Papers, 61 (2009), 1-27, p. 5.

${ }^{14}$ Randolph M. Siverson and Harvey Starr, 'Opportunity, Willingness, and the Diffusion of War', American Political Science Review, 84 (1990), 47-67, pp. 48-9.

${ }^{15}$ Harvey Starr, 'Joining Political and Geographic Perspectives: Geopolitics and International Relations', International Interactions, 17 (1991), 1-9, pp. 4-5, emphasis in original; see also Kelly M. Kadera, 'Transmission, Barriers, and Constraints: A Dynamic Model of the Spread of War', Journal of Conflict Resolution, 42 (1998), 367-87.

${ }^{16}$ Harvey Starr, "Opportunity" and "Willingness" as Ordering Concepts in the Study of War', pp. $364-5$.

${ }^{17}$ Siverson and Starr, 'Opportunity, Willingness, and the Diffusion of War', p. 49.

${ }^{18}$ Siverson and Starr, The Diffusion of War; Werner and Lemke, 'Opposites Do Not Attract'. 
opportunities and willingness, the less time it will take that nation to become involved in the war'. ${ }^{19}$ Furthermore, among the opportunity variables, they expected states with direct contiguity to join sooner than those with cross-water and colonial borders. Among the willingness variables, they expected states with defence pacts to join earliest, followed by those with neutrality pacts and ententes, as they 'view these types of alliance commitments as forming a rough ordinal index of willingness' ${ }^{20}$ While their expectations for contiguity were supported, those for alliances were not. States that had defence pacts with the initial belligerents did not join earliest, which was unexpected because defence pacts are seen as the strongest form of alliance commitment. We believe this result illustrates the need to take both side selection and timing into consideration, since it is likely that some of the factors that would motivate states to join the initiator would not necessarily influence (or would influence differently) the decision to join the target.

Werner and Lemke build upon Siverson and Starr by incorporating side selection and including a larger number of variables, particularly for capturing willingness. ${ }^{21}$ However, they did not consider the timing of third-party joining and excluded contiguity from their analysis. In addition, the research designs of both studies only included states that actually joined a conflict, and excluded states that could have joined a conflict, which we argue below is a problem that affects their statistical results and therefore their conclusions.

While Siverson and Starr found less support for willingness, Werner and Lemke found that willingness plays a considerable role. Werner and Lemke found that 'differences in domestic institutions and, under some conditions, power and alliance commitments, have a significant impact on foreign policy decisions'. ${ }^{22}$ The differences in the results might be due to the different research designs, but this requires further exploration given the central position of willingness in the framework. In fact, Siverson and Starr's lack of support for willingness is surprising, given that factors associated with willingness have been found to play a bigger role than those associated with opportunity. ${ }^{23} \mathrm{We}$ extend the framework in order to address this discrepancy.

${ }^{19}$ Siverson and Starr, The Diffusion of War, p. 76, emphasis in original.

${ }^{20}$ Siverson and Starr, The Diffusion of War, p. 50.

${ }^{21}$ Werner and Lemke, 'Opposites Do Not Attract'.

22 Werner and Lemke, 'Opposites Do Not Attract', p. 545

${ }^{23}$ Furlong et al., 'Geographic Opportunity and Neomalthusian Willingness'; Most and Starr, Inquiry, Logic and International Politics.

${ }^{24}$ David Kinsella and Bruce Russett, 'Conflict Emergence and Escalation in Interactive International Dyads', Journal of Politics, 64 (2002), 1045-68, pp. 1049-50. 
governance, economic interdependence, and membership in international organizations, all of which are indicative of dyadic interactions that communicate private information - should become relatively more important than they were at earlier stages. ${ }^{25}$

The additional factors referred to by Kinsella and Russett are the willingness variables. This argument does not take into account which side initiated the conflict and which side was targeted. The identity of the initial belligerents is important because it provides information that third parties will find pertinent when deciding whether or not to join, and on which side. Indeed, expectations of third-party joining affect the behaviour of initial belligerents, which may adjust their demands to dissuade a third party from joining. ${ }^{26}$

While there have been instances when an initiator took the first militarized action because future and alternative prospects looked bleak, it has been shown that initiators are more likely to challenge weak targets that they believe will not receive outside assistance, so the distribution of military capability is likely to favour the initiator. ${ }^{27}$ Thus potential joiners might assume that the initiator has private information on how the process of conflict will unfold in its favour, and has an incentive to misrepresent its resolve or military capabilities during bargaining. However, strategically keeping the opposing side uncertain about military capabilities increases the chance of war and is also likely to make third parties increasingly concerned. ${ }^{28}$

The initiator's advantage is likely to influence both when and which side third parties decide to join. In particular, as the discrepancy in military capability between the initial belligerents increases, the duration of the dispute is likely to be shorter, which in turn decreases the window within which third parties can join. If third parties expect the initiator to win and to do so quickly, they may be more inclined to join the dispute sooner on the side of the initiator than on the side of the target, perhaps because they expect the initiator to win quickly or because their expected costs are lower due to the anticipated shortened duration of the conflict.

The initiator's advantage may cause third parties to decide that joining the target may be more costly. However, there may also be costs of not joining the target, and in some situations these costs may be higher than joining. For example, if the security of a potential joiner is jeopardized by not joining the target, it is more likely to join. Thus, while the initial information may indicate that the initiator has an advantage, the strength of the initiator may have implications for the security of the potential joiner.

As discussed above, willingness refers to the motivations and goals of decision makers that influence their decision to join a conflict or remain neutral. If potential joiners believe

${ }^{25}$ Kinsella and Russett, 'Conflict Emergence and Escalation in Interactive International Dyads', p. 1050 .

${ }^{26}$ Alastair Smith, 'Alliance Formation and War', International Studies Quarterly, 39 (1995), 405-25; Alastair Smith, 'To Intervene or Not to Intervene: A Biased Decision', Journal of Conflict Resolution, 40 (1996), 16-40; Werner, 'Deterring Intervention'.

${ }^{27}$ Melin and Koch, 'Jumping into the Fray'; Scott Sigmund Gartner and Randolph M. Siverson, 'War Expansion and War Outcome', Journal of Conflict Resolution, 40 (1996), 4-15; Paul K. Huth, Extended Deterrence and the Prevention of War (New Haven, Conn.: Yale University Press, 1988); Bruce Bueno de Mesquita, The War Trap (New Haven, Conn.: Yale University Press, 1981); Paul K. Huth, 'Major Power Intervention in International Crises, 1918-1988', Journal of Conflict Resolution, 42 (1998), 744-70; Werner, 'Deterring Intervention'.

28 James Fearon, 'Rationalist Explanations for War', International Organization, 49 (1995), 379-414; Adam Meirowitz and Anne E. Sartori, 'Strategic Uncertainty as a Cause of War', Quarterly Journal of Political Science, 3 (2008), 327-52. 
the initiator has an advantage at the outset of a dispute, the willingness variables should increase the probability of joining the initiator rather than the target. If the initial information suggests that the initiator has an advantage, there is little reason to delay joining the initiator; in general, states are more likely to join the initiator more quickly than the target.

Below we discuss several variables within the opportunity and willingness framework that influence a third party's decision to join an ongoing conflict. While some of these factors (such as geographic proximity and democracy) have been considered in extant research in terms of timing and side selection, other factors (such as autocracy, rivalry and previous major power joining) have not been considered in relation to how they influence the timing of third-party joining and which side they join. ${ }^{29}$ We discuss the influence of each factor on the risk (that is, timing) of third-party joining and how the risk of joining differs between a decision to join the initiator and a decision to join the target. Since we use an event history model to conduct our empirical analysis, we present our hypotheses in terms of how each factor affects the risk of joining. If a factor increases (decreases) the risk of joining it decreases (increases) the time until joining is expected to occur.

\section{Opportunity}

Since opportunity is linked to whether a state is able to get involved in a conflict, we focus on capability and geographic proximity. These factors have been put forward as 'the most physically apparent determinants of opportunity'. ${ }^{30}$

Capability. After a conflict begins, a potential joiner is likely to consider how its capability contribution will influence the conflict's eventual outcome and how long it will take the initial belligerent it joins to reach that outcome, preferably a victory. The realist tradition is particularly concerned about capability because it is central to the balance of power in the international system. ${ }^{31}$ According to balance of power theory, states are concerned with the acquisition of power by other states because it threatens their own security and survival. Military conflict provides states with an opportunity to gain additional power that, in turn, could lead to a change in the distribution of power in the international or regional system. As a result, a third party is likely to consider the threat that an ongoing militarized conflict poses to its external security when making its joining decision. ${ }^{32}$ Stoll asserts that 'findings across a variety of studies are consistent with the premise that states are motivated by basic realpolitik considerations when they decide to join or abstain from a war'. ${ }^{33}$

Regardless of the distribution of capabilities between the initial belligerents, third-party joining increases the probability of winning for the initial belligerent it joins, thus changing the dynamics of the dispute. For example, if there is an approximate balance of capabilities

${ }^{29}$ Melin and Koch, 'Jumping into the Fray'.

${ }^{30}$ David H. Clark and Patrick M. Regan, 'Opportunities to Fight: A Statistical Technique for Modeling Unobservable Phenomena', Journal of Conflict Resolution, 47 (2003), 94-115, p. 101.

${ }^{31}$ Hans Morgenthau, Politics Among Nations (New York: Knopf, 1948); Kenneth Waltz, Theory of International Politics (Reading, Mass.: Addison-Wesley, 1979).

${ }^{32}$ Stacy Haldi, Why Wars Widen: A Theory of Predation and Balancing (Portland, Ore.: Frank Cass, 2003).

${ }^{33}$ Ric Stoll, 'The Evolution of War', in Stuart A. Bremer and Thomas R. Cusack, eds, The Process of War: Advancing the Scientific Study of War (Amsterdam: Gordon and Breach Publishers, 1995), pp. $129-160$, p. 136. 
between the initial belligerents, then joining by even a relatively weak state can shift the balance to one initial belligerent, potentially leading to a (quicker) victory for the joined side. Indeed, in some conflicts, such as World War I, third parties were actively solicited by both initial belligerents.

Of particular importance are instances when a third party joins the weaker side in an imbalanced conflict. Most realists and neorealists anticipate that third parties would join the weaker side in this instance, since failure to do so can result in the more powerful conquering the weaker. ${ }^{34}$ When a third party joins the weaker side, it balances against the stronger side and increases the weaker side's chances of victory. In this case, the third party's motives are at least partially interpreted as preventing the stronger side from becoming even more dominant. Some realists have argued that states might bandwagon with (instead of balancing against) the stronger side. For example, Walt argues that weaker states are more likely to join the stronger side (that is, bandwagon) while stronger states are more likely to join the weaker side (balance). ${ }^{35}$ States might choose to bandwagon in order to appease the stronger side or to achieve certain goals. ${ }^{36}$

While Siverson and Starr exclude capability, Werner and Lemke find that as the initiator of a dispute becomes more powerful, third parties are more likely to join on its side, but as the target becomes more powerful, third parties are less likely to join on its side. ${ }^{37}$ Werner and Lemke argue that these findings lend support to the revisionist realists (for example, Schweller). ${ }^{38}$ Similarly, Reiter and Stam find no support for a weaker target receiving third-party assistance, and Corbetta reports limited support for balancing in militarized conflicts. ${ }^{39}$ In contrast, Melin and Koch find that a third party's capability itself or relative to the initial belligerents, does not influence whether to join the initiator but does influence joining quickly on the side of the target. In short, there appears to be no consistent empirical support for whether balancing or bandwagoning is more prevalent. ${ }^{40}$

Although joining by relatively weak third parties can affect the dynamics of an ongoing conflict, the more powerful a third party is relative to the initial belligerents, the greater its ability to influence the conflict's outcome. As a third party's capability increases, its opportunity for joining also increases. We expect that third parties with higher levels of material capability (relative to the initial belligerents) are more likely to join an ongoing dispute, and will do so sooner, than less capable third parties. ${ }^{41}$ If a potential joiner with sufficient capability to significantly alter the chances of victory for one side delays joining, other third parties could join, or its favoured side could become significantly weaker as the dispute persists. In either case, a third party's ability to influence the outcome of the dispute decreases.

${ }^{34}$ Morgenthau, Politics Among Nations; Waltz, Theory of International Politics.

${ }^{35}$ Stephen Walt, The Origins of Alliances (Ithaca, N.Y.: Cornell University Press, 1987).

${ }^{36}$ Walt, The Origins of Alliances; Randall L. Schweller, 'Bandwagoning for Profit: Bringing the Revisionist State Back In', International Security, 19 (1994), 72-107.

${ }^{37}$ Siverson and Starr, The Diffusion of War; Werner and Lemke, 'Opposites Do Not Attract'.

${ }^{38}$ Werner and Lemke, 'Opposites Do Not Attract'; Schweller, 'Bandwagoning for Profit'.

${ }^{39}$ Reiter and Stam, Democracies at War; Corbetta, 'Determinants of Third Parties' Intervention and Alignment Choices'.

${ }^{40}$ Melin and Koch, 'Jumping into the Fray'.

${ }^{41}$ Michael F. Altfeld and Bruce Bueno de Mesquita, 'Choosing Sides in Wars', International Studies Quarterly, 23 (1979), 87-112; Stuart A. Bremer, 'National Capabilities and War Proneness', in J. David Singer, ed., The Correlates of War II: Testing Some Realpolitik Models (New York: Free Press, 1980), pp. 57-82; Huth, Extended Deterrence. 
Delaying entry is particularly relevant for third parties that would join the target, as initiators are more likely to challenge weak states, potentially reducing the length of the conflict and the time in which a third party must make its decision. ${ }^{42}$ Since initiators are more likely to challenge weak states, their victory might be seen as particularly threatening to the global or regional distribution of power. By joining the target, a third party can help ensure the survival of the target and prevent the initiator from increasing its power - or at least from acquiring enough power to alter the status quo, all of which are vital concerns to states, according to realists. Walt argues that 'states that are viewed as aggressive are likely to provoke others to balance against them'. ${ }^{43}$ While relatively more capable third parties may also join the initiator, we expect there to be less urgency compared to joining the target. In sum, while we expect that relatively more capable third parties have a higher risk of joining an ongoing dispute than relatively less capable third parties, we expect the risk of joining to be higher for joining the target than the initiator.

HYPOTHESIS 1: As the capability contribution of a third party increases, the risk of joining the target is higher than the risk of joining the initiator.

Geographic proximity. A third party's geographic proximity to an ongoing conflict is likely to influence its assessment of how threatening the conflict is to its external security. Third parties in close proximity to the conflict, especially contiguous ones, are more likely to be sensitive to local events than those farther away. Moreover, local conflict is naturally more threatening to these proximate states. While Regan finds that contiguity does not affect the decision to join in civil wars, the situation in interstate conflict appears to be different. ${ }^{44} \mathrm{~A}$ third party's geographic proximity to the initial belligerents has been shown to increase the likelihood that a conflict will expand. ${ }^{45}$ One likely reason is that geographic proximity provides third parties with an opportunity to preserve their external security.

This finding was illustrated in both of the Balkan Wars, where many nearby states rushed to gain land first from the Ottoman Empire and then from Bulgaria. More recently, the breakup of Yugoslavia generated fears that other nearby states would be pulled into the conflicts. Additionally, transportation costs make participation in long-distance conflicts more difficult due to the loss-of-strength gradient; thus proximate potential joiners are more likely to influence a conflict than non-proximate third parties. ${ }^{46}$ In fact, it is hard to imagine Greece and Ethiopia making the trip to fight on the Korean Peninsula during the Korean War if it had not been for the transportation assistance that these states received from the United States. In the case of a contiguous third party, its participation can open up an additional front that the side it aligns against will now need to defend, in turn increasing the probability of victory for the side joined. Proximity could also present a third party with an opportunity to acquire additional territory by joining the conflict.

${ }^{42}$ Gartner and Siverson, 'War Expansion and War Outcome'.

${ }^{43}$ Walt, The Origins of Alliances, p. 25.

${ }^{44}$ Patrick Regan, Civil Wars and Foreign Powers (Ann Arbor: University of Michigan Press, 2002).

45 Benjamin Most, Philip Schrodt, Randolph Siverson and Harvey Starr, 'Borders and Alliance Effects in the Diffusion of Major Power Conflict, 1816-1965', in Charles S. Gochman and Alan Ned Sabrosky, eds, Prisoners of War?: Nation-States in the Modern Era (Lexington, Mass.: Lexington Books, 1990), pp. 209-29; Siverson and Starr, The Diffusion of War; Raknerud and Hegre, 'The Hazard of War'.

${ }^{46}$ Boulding, Conflict and Defense. 
Siverson and Starr found that geographically contiguous states would take less time to join a war, which led them to conclude that opportunity had a greater effect on the timing of joining than willingness. ${ }^{47}$ In other analyses, Siverson and Starr differentiated between the initiator and target, but they did not do so in their analysis of timing. ${ }^{48}$ Also, while Werner and Lemke build upon Siverson and Starr in many ways, they do not examine the role of geographic proximity. ${ }^{49}$ However, Melin and Koch find that as the distance between a potential joiner and an initial belligerent increases, the time until joining the initiator or the target increases. ${ }^{50}$

We expect a third party's geographic proximity to the ongoing dispute to increase the risk of participation. We also expect third parties that are contiguous to the initiator to be more likely to join the target, and third parties that are contiguous to the target to be more likely to join the initiator. Furthermore, we expect the risk to be higher for joining the target. This expectation follows from our earlier argument that third parties may conclude that it will be more costly if they do not join the target, since a third party contiguous to the initiator that does not join the target may be at a disadvantage in the long run. If the initiator wins, the third party may end up facing a stronger neighbour in the future - a situation that will reduce its security and raise the level of threat it may face from its neighbour.

HYPOTHESIS 2: A third party contiguous to the initiator has a higher risk of joining the target compared to the risk that a third party contiguous to the target will join the initiator.

\section{Willingness}

Siverson and Starr found that willingness, in the form of alliances, played less of a role than opportunity in the timing of third-party joining in ongoing conflicts. ${ }^{51}$ In contrast, Werner and Lemke found more support for factors associated with willingness, such as regime similarity, but did not consider timing in their analyses. ${ }^{52}$ Since willingness refers to what motivates states to join an ongoing conflict, we consider how regime type, alliances, rivalry and previous major power joining influence the timing and what side a third party joins.

Regime type. States with similar domestic political institutions are likely to be more familiar with each other's decision-making processes, thus decreasing the uncertainty between them and making it easier for them to build mutual ties. Past research shows that institutional similarity influences whether states engage in violent conflict with each other. Findings on the existence of both a democratic peace, and possibly a dictatorial peace, are relevant with respect to which side a third party will join. ${ }^{53}$ Previous research

47 Siverson and Starr, The Diffusion of War.

48 Siverson and Starr, The Diffusion of War.

49 Werner and Lemke, 'Opposites Do Not Attract'; Siverson and Starr, The Diffusion of War.

50 Melin and Koch, 'Jumping into the Fray'.

51 Siverson and Starr, The Diffusion of War.

52 Werner and Lemke, 'Opposites Do Not Attract'.

53 Mark Peceny, Caroline C. Beer and Shannon Sanchez-Terry, 'Dictatorial Peace?', American Political Science Review, 96 (2002), 15-26; Bruce Russett and John R. Oneal, Triangulating Peace: Democracy, Interdependence, and International Organizations (New York: W.W. North \& Company, 2001). 
demonstrates that third parties are more likely to join states with similar domestic political regimes. ${ }^{54}$ Werner and Lemke find that institutional similarities are important in a state's decision to join and that there is little merit to the argument that 'opposites attract'. ${ }^{55}$ In 1938, US President Franklin Roosevelt assured British Prime Minister Neville Chamberlain that Great Britain would have 'the industrial resources of the American nation behind him in the event of war with the dictatorships, ${ }^{56}$

The primary focus of past research has been on explaining the behaviour of democracies. Democracies do not shy away from joining, and tend to join ongoing conflicts more frequently than autocracies. ${ }^{57}$ The two world wars and the Gulf War are examples of democracies joining a coalition against a small number of autocracies. This pattern fits with Lake's argument that democracies should be adept at balancing against other regimes by forming democratic countercoalitions. ${ }^{58}$ Similarly, Choi maintains that democracies are more likely to win as the number of democracies they have on their side increases. ${ }^{59}$

We expect regime similarity to differ for the timing of third parties' decisions to join the initiator or the target. Melin and Koch did not find much support for democracy contributing to joining on the initiator side. ${ }^{60}$ Gartzke and Gleditsch concluded that democracies are less reliable allies. ${ }^{61}$ Reiter and Stam found no evidence that democracies are more likely to join democratic targets. ${ }^{62}$ In part these findings indicate that leaders of democratic states want to avoid situations of risk that could lead to national (and potentially electoral) defeat. As initiators are more likely to target weak states, and since democracies are more likely to initiate conflicts that they expect to win, democracies might resist joining a democratic target but may not have the same reservations about joining a democratic initiator. ${ }^{63}$ Third parties are likely to perceive the chance of joining the losing side as being low in the case of joining a democratic initiator and high in the case of a democratic target. Thus we expect the time until democracies join democratic initiators to be shorter than the time until joining democratic targets.

The extent to which autocratic third parties behave similarly to democratic third parties in their propensity to join has been less explored. It is debatable whether autocracies have

${ }^{54}$ Corbetta, 'Determinants of Third Parties' Intervention and Alignment Choices'; Huth, 'Major Power Intervention'; Raknerud and Hegre, 'The Hazard of War'; Reiter and Stam, Democracies at War; Werner and Lemke, 'Opposites Do Not Attract'.

${ }_{55}$ Werner and Lemke, 'Opposites Do Not Attract'.

56 John A. Thompson, 'Conceptions of National Security and American Entry into World War II', Diplomacy and Statecraft, 16 (2005), 671-97, p. 673, emphasis added.

${ }^{57}$ Raknerud and Hegre, 'The Hazard of War'.

58 David A. Lake, 'Powerful Pacifists: Democratic States and War', American Political Science Review, 86 (1992), 24-37.

${ }_{59}$ Ajin Choi, 'Democratic Synergy and Victory in War, 1816-1992', International Studies Quarterly, 47 (2004), 663-82.

${ }^{60}$ Melin and Koch, 'Jumping into the Fray'.

${ }^{61}$ Erik Gartzke and Kristian Skrede Gleditsch, 'Why Democracies May Actually Be Less Reliable Allies', American Journal of Political Science, 48 (2004), 775-95.

${ }^{62}$ Reiter and Stam, Democracies at War; see also Michael Mousseau, 'Peace in Anarchy: Democratic Governance and International Conflict' (doctoral dissertation, State University of New York at Binghamton, 1997); Melin and Koch, 'Jumping into the Fray'.

${ }^{63}$ Bruce Bueno de Mesquite, James D. Morrow, Randolph M. Siverson and Alastair Smith, 'An Institutional Explanation of the Democratic Peace', American Political Science Review, 93 (1999), 791-807; Reiter and Stam, Democracies at War. 
the same set of attachments to each other as democracies, partly because many different regime types can be labelled autocratic. However, examples such as the Holy Alliance, Axis powers, Three Emperors League and Triple Alliance demonstrate that non-democratic regime types also join together. Werner and Lemke show that autocracies also consider regime similarities and differences in their alignment decisions, and found that autocracies are more prone to honour their alliance commitments, perhaps because democratic allies were less likely to be targeted in the first place.$^{64}$ Raknerud and Hegre found that autocracies join fellow autocracies, but to a lesser extent than democracies join with other democracies. ${ }^{65}$ Corbetta also found that autocracies join other autocracies. ${ }^{66}$ In terms of autocratic third parties, we expect the risk of joining an autocratic initiator to be higher than the risk of joining an autocratic target. While autocratic regimes might be less sensitive to some types of costs (such as electoral costs) associated with joining one of the initial belligerents and ending up on the losing side, they also face costs such as regime survival.

HYPOTHESIS 3: A democratic (autocratic) third party has a higher risk of joining a democratic (autocratic) initiator than a democratic (autocratic) target.

Alliance. The importance of alliances as a primary reason for conflict expansion has been widely examined ${ }^{67}$ Siverson and Starr find that alliances increase the willingness of third parties to join ongoing conflicts. ${ }^{68}$

While alliances might increase the willingness of third parties to join ongoing disputes, the central question is whether third parties will honour their alliance commitments. Potential joiners are likely to consider the costs of maintaining their alliance commitments during an ongoing conflict. Third parties that fail to do so face potential reputation costs, the potential loss of an ally and a potential victory by a non-ally. This is similar to Altfeld and Bueno de Mesquita's argument that alliances influence a third party's utility for having a particular belligerent win. ${ }^{69}$ There is some evidence that states tend to honour their alliance commitments. ${ }^{70}$ Leeds found that 80 per cent of allied states fulfilled their alliance obligations when the conditions of the alliance were invoked by war. ${ }^{71}$

64 Werner and Lemke, 'Opposites Do Not Attract'.

65 Raknerud and Hegre, 'The Hazard of War'.

${ }^{66}$ Corbetta, 'Determinants of Third Parties' Intervention and Alignment Choices'.

67 Altfeld and Bueno de Mesquita, 'Choosing Sides in Wars'; Chae-Han Kim, 'Third-Party Participation in Wars', Journal of Conflict Resolution, 35 (1991), 659-77; Jack S. Levy, 'The Contagion of Great Power War Behavior, 1495-1975', American Journal of Political Science, 26 (1982), 562-84; Randolph M. Siverson and Joel King, 'Alliances and the Expansion of War, 1815-1965', in J. David Singer and Michael Wallace, eds, To Augur Well: Early Warning Indicators in World Politics (Beverly Hills, Calif.: Sage Publications, 1979), pp. 37-49; Siverson and Starr, The Diffusion of War; Smith, 'To Intervene or Not to Intervene'; Werner and Lemke, 'Opposites Do Not Attract'.

${ }^{68}$ Siverson and Starr, The Diffusion of War; see also Alan Ned Sabrosky, 'Interstate Alliances: Their Reliability and the Expansion of War', in Singer, The Correlates of War II, pp. 161-98; Most et al., 'Borders and Alliance Effects'.

69 Altfeld and Bueno de Mesquita, 'Choosing Sides in Wars'.

${ }^{70}$ Corbetta, 'Determinants of Third Parties' Intervention and Alignment Choices'; Brett Ashley Leeds, 'Alliance Reliability in Times of War: Explaining State Decisions to Violate Treaties', International Organization, 57 (2003), 801-27; Brett Ashley Leeds, 'Do Alliances Deter Aggression? The Influence of Military Alliances on the Initiation of Militarized Interstate Disputes', American Journal of Political Science, 47 (2003), 427-39; Smith, 'To Intervene or Not to Intervene'.

71 Leeds, 'Alliance Reliability in Times of War'. 
An interesting exception to this finding is that Gartzke and Gleditsch concluded that democracies were less likely to come to their allies' assistance than non-democracies. ${ }^{72}$

If a challenger knows that a target has an alliance and is still willing to take militarized action, this suggests that it does not believe the alliance is reliable. A state is more likely to issue a challenge if it believes that the target's ally will not come to its assistance or if it is not concerned by the assistance that the ally will provide, perhaps because it estimates that the assistance will be too little or too late. ${ }^{73}$ Thus while many states might honour their commitments, there is little support that alliances result in extended deterrence success. $^{74}$

Past research has primarily distinguished between three types of alliances: defence pacts, ententes and non-aggression pacts. Defence pacts are argued to have the greatest effect on third parties' decisions, since they require members to militarily aid each other in the event of a conflict. Non-aggression pacts, which require members to remain neutral or at least not use force against other members in the event of a dispute, have been found to slow the expansion process, though with conflicting levels of support. ${ }^{75}$ Ententes are argued to have less effect than defence pacts, as they only require members to consult with each other if a dispute occurs.

While alliances are argued to be a crucial element of the expansion process, most existing research has not considered how the type of alliance influences the timing of third-party joining the initiator compared to the target. We consider three types of alliance obligations: defence, offence and neutrality. Leeds, Ritter, Mitchell and Long demonstrate some of the advantages of relying on this classification rather than defence, ententes and non-aggression pacts. ${ }^{76}$

A potential joiner that has a defence, offence or neutrality pact with an initial belligerent is likely to share common views on foreign policy. When an ally initiates a conflict, we expect states that share a defence or offence pact with the initiator to join the initiator. If a potential joiner does not join, it can lead to reputation costs, which are likely to have implications beyond the current conflict and may weaken the allies' mission. These costs also exist for potential joiners that have defence or offence pacts with the target; thus we also expect them to increase the risk of joining the target. The costs of not fulfilling a defence or offence pact with a state that is targeted will also be high, but the costs of joining the target are likely to be higher and may deter some states from joining. Neutrality pacts require an explicit promise to not join a conflict against a fellow signatory. While much weaker than defence pacts, we also expect them to increase the risk of joining. If a potential joiner has a neutrality pact with an initiator that should increase the risk of joining the initiator. If a potential joiner has a neutrality pact with the target that should increase the risk of joining the target, although we expect it to be less costly to join the initiator.

HYPOTHESIS 4 : A third party with a defence (or offence or neutrality) pact has a higher risk of joining the initiator than the target.

402

403

404

405

406

407

408

409

410

411

412

413

414

415

416

417

418

419

420

421

422

423

424

425

426

427

428

429

430

431

432

433

434

435

436

437

438

${ }^{72}$ Gartzke and Gleditsch, 'Why Democracies May Actually Be Less Reliable Allies'.

73 Altfeld and Bueno de Mesquita, 'Choosing Sides in Wars'; Smith, 'Alliance Formation and War'.

74 Bueno de Mesquita, The War Trap; Huth, Extended Deterrence; Werner, 'Deterring Intervention'.

${ }^{75}$ Kadera, 'Transmission, Barriers, and Constraints'; Kim, 'Third-Party Participation in Wars'; Raknerud and Hegre, 'The Hazard of War'; Siverson and Starr, The Diffusion of War.

${ }^{76}$ Brett Ashley Leeds, Jeffrey M. Ritter, Sara McLaughlin Mitchell and Andrew G. Long, 'Alliance Treaty Obligations and Provisions, 1815-1944', International Interactions, 28 (2002), 237-60. 
Rivalry. The presence of an entrenched hostility (that is, rivalry) between a potential joiner and one of the initial belligerents is likely to influence a third party's assessment of how threatening the ongoing conflict is to its external security and therefore its willingness to join. States involved in rivalries are likely to perceive each other as aggressive. ${ }^{77}$ Thus when the rival of a third party is involved in a conflict with another state, its willingness to become involved increases since it can inflict costs on its rival and/or prevent it from acquiring additional power by joining the conflict on the opposing side. By joining a rival's adversary, a potential joiner can improve its external security. Several important wars of the last two centuries include countries joining on the side opposite their rival, such as the Korean War and World Wars I and II.

Kim examined alliance commitments and found that third parties are more likely to join an ongoing conflict to aid friends than to oppose foes. ${ }^{78}$ This finding suggests that rivalries might have less of an influence than alliances. Melin and Koch report that a shared enemy between either side and the third party will increase the risk of joining, although they do not consider whether the states involved were rivals. ${ }^{79}$ The 'enemy of my enemy is my friend' rationale leads us to believe that third parties will take the chance to capitalize on the possibility of dealing a decisive blow to an adversary even if there is not a good relationship between the potential joiner and the other initial belligerent. In this case, a third party does not need to feel any particular fondness for the side it joins, but joins anyway because of a strong dislike for the opposing side, its rival. In their research on third-party joining in civil wars, Findley and Teo find that the risk of joining the opposition increases by about 11 times when a rival joins the government. ${ }^{80}$ They also report that when a rival joins the opposition, the risk of joining the government increases by about 4 times.

We expect a rivalry to increase the risk of a third party joining a conflict, and that the risk is higher for joining the side opposite its rival. If the rival of a potential joiner is the initiator (target), the potential joiner is more likely to join the target (initiator). We also expect that rivals with the initiator will join the target sooner than rivals with the target will join the initiator. If a stronger state attacks a rival, a potential joiner may remain neutral in the hopes that the initiator will win without its involvement, in which case a rival would reap the benefits of victory without the costs. In contrast, if the initiator is the rival, we expect the rival to intervene on the side of the target in order to prevent its enemy from scoring a victory.

HYPOTHESIS 5: A third party that has a rivalry with the initiator has a higher risk of joining the target than a third party that has a rivalry with the target has of joining the initiator.

Previous major power joining. When making their decisions about whether or not to join an ongoing conflict, third parties are likely to consider the participation of other third parties, especially if those other parties are influential states in the international system

77 D. Scott Bennett, 'Security, Bargaining, and the End of Interstate Rivalry', International Studies Quarterly, 40 (1996), 157-83; Paul F. Diehl and Gary Goertz, War and Peace in International Rivalry (Ann Arbor: University of Michigan Press, 2000); William R. Thompson, 'Identifying Rivals and Rivalries in World Politics', International Studies Quarterly, 45 (2001), 557-86.

${ }^{78} \mathrm{Kim}$, 'Third-Party Participation in Wars'.

79 Melin and Koch, 'Jumping into the Fray'.

${ }^{80}$ Michael G. Findley and Tze Kwang Teo, 'Rethinking Third-Party Interventions into Civil Wars: An Actor-Centric Approach', Journal of Politics, 68 (2006), 828-37. 
and have the potential to dramatically influence the outcome of the conflict. We focus on how the prior joining by major powers influences the willingness of other third parties to join. When a major power joins an ongoing conflict, it is likely to lead other third parties to reevaluate their decision to join. ${ }^{81}$ Thus when deciding whether or not to join, potential joiners will not only consider the initial belligerents of the conflict but also whether a major power has previously joined.

While this argument has not received much empirical attention, Yamamoto and Bremer examined how major power joining influences other major powers' decisions to join an ongoing conflict. ${ }^{82}$ They found that a major power's decision to join was highly dependent on the participation of other major powers. ${ }^{83}$ However, the decision of a major power to join influences the decisions not only of other major powers, but of all other potential joiners as well, and has implications for the balancing and bandwagoning debate discussed above. For example, in the Korean War many states joined after the United States did so. Once a major power joins, other states might conclude that the side the major power joined is much more likely to win. In fact, it is noteworthy that minor powers were unwilling to join opposite the United States, as China alone fought on the side of North Korea. In this case, less capable states might have believed that they could gain by joining on the side that the major power (the United States) joined. In return for joining the side the major power joined in an ongoing conflict, a minor power may increase the likelihood of obtaining benefits such as support from that same major power in any future conflicts in which the minor power becomes involved, increased trade, financial aid or inclusion in an international organization such as NATO. Thus, participation by a major power should increase the probability that other potential joiners will enter on the same side. And since joining by a major power will likely reduce the length of the dispute and the time in which additional third parties may obtain any benefits from joining, the risk of joining either side is higher when major power third parties have previously joined.

HYPOTHESIS 6: The risk of a third party joining the initiator (target) if a major power has previously joined the initiator (target) is higher than if a major power has not previously joined the initiator (target).

We use the Militarized Interstate Dispute (MID) dataset to identify a sample of disputes, the timing of third-party joining (if any) in those disputes and the side on which that joining (if any) occurred. ${ }^{84}$ Our sample only includes MIDs that had a dispute hostility level of 4 or 5 (that is, 'use of force' or 'interstate war') and that lasted for more than one

${ }^{81}$ Yoshinobu Yamamoto and Stuart A. Bremer, 'Wider Wars and Restless Nights: Major Power Intervention in Ongoing War', in Singer, The Correlates of War II, pp. 199-229.

${ }^{82}$ Yamamoto and Bremer, 'Wider Wars and Restless Nights'.

${ }^{83}$ Yamamoto and Bremer, 'Wider Wars and Restless Nights'; Kim, 'Third-Party Participation in Wars'.

${ }^{84}$ Faten Ghosn, Glenn Palmer and Stuart A. Bremer, 'The MID3 Data Set, 1993-2001: Procedures, Coding Rules, and Description', Conflict Management and Peace Science, 21 (2004), 133-54. A detailed description of the construction of the dataset and variables, as well as summary statistics and additional results can be found in the web appendix. All of the data used, unless otherwise specified, was complied using EUGene v3.204. See D. Scott Bennett and Allan C. Stam, 'EUGene: A Conceptual Manual', International Interactions, 26 (2000), 179-204. 
day between 1816 and 2001. We use these MIDs because they indicate that military force has been used by at least one state. These are the most serious disputes, and we expect third-party decisions to be important during these disputes.

We follow the MID codings in identifying the initiator, target and third-party joiners. The initiator is defined as the side that took the first codeable militarized action, while the target is defined as the recipient of that action. ${ }^{85} \mathrm{We}$ acknowledge that the label 'initiator' may not truly reflect which state initiated the dispute in the broader sense of 'instigator', but we believe that regardless of how the initial belligerents are labelled (initiator and target, aggressor and victim), the factors that influence when and which side third parties join should differ by side. Additionally, this way of determining initiators and targets, while limited, is standard in most research using the MID dataset, including the conflict expansion literature. ${ }^{86} \mathrm{~A}$ state is coded as having joined a MID if it participated in the MID for at least one day after the first day of the MID.

We use a triadic approach to examine third-party joining in ongoing MIDs. ${ }^{87}$ Some extant research only includes third parties that actually joined a MID in their sample, which is problematic because it excludes important information about third parties that could have joined a MID but chose not to. ${ }^{88}$ Since a third party is continually updating its decision about whether to join or remain neutral as a dispute persists, a decision not to join at one point in time does not preclude joining in the future. Our dataset includes all third parties that could potentially join a MID, which we define as all states in the international system (except the initial belligerents) during the MID according to the Correlates of War (COW) State System Membership List. ${ }^{89}$

We restrict our attention to politically relevant triads. A triad is defined as being politically relevant if: (1) the potential joiner is contiguous to at least one of the initial belligerents or (2) the potential joiner or one of the initial belligerents is a major power. ${ }^{90}$ For each year in each MID we include the initiator, the target and all potential joiners that meet the two conditions that define a politically relevant triad. ${ }^{91}$ For example, consider World War I, in which Austria-Hungary was the initiator and Serbia was the target. For each year of the MID (1914-1918), Greece is a potential joiner until 29 June 1917, when it joined Serbia, and Switzerland is a potential joiner until the end of the war

${ }^{85}$ Ghosn et al., 'The MID3 Data Set'.

86 Melin and Koch, 'Jumping into the Fray'; Siverson and Starr, The Diffusion of War; Werner and Lemke 'Opposites Do Not Attract'; D. Scott Bennett and Allan C. Stam, The Behavioral Origins of War (Ann Arbor: University of Michigan Press, 2004).

${ }^{87}$ Corbetta, 'Determinants of Third Parties' Intervention and Alignment Choices'; Melin and Koch, 'Jumping into the Fray'; Mousseau, Peace in Anarchy; Reiter and Stam, Democracies at War; Werner and Lemke, 'Opposites Do Not Attract'.

${ }^{8}$ Siverson and Starr, The Diffusion of War; Werner and Lemke, 'Opposites Do Not Attract'.

${ }^{89}$ Corbetta, 'Determinants of Third Parties' Intervention and Alignment Choices'; Melin and Koch, 'Jumping into the Fray'; Correlates of War Project State System Membership List, available at http:// correlatesofwar.org (accessed 26 October 2009).

90 Reiter and Stam, Democracies at War. We focus on politically relevant triads to avoid inflating our sample by including third parties for which there is only a small probability of joining. Politically relevant triads account for about 40 per cent of all triads. In the web appendix we report the results from the full sample of potential joiners. Our findings are similar regardless of whether our sample includes all triads or only politically relevant triads.

91 If there were multiple initial belligerents (that is, more than one initiator and/or more than one target), then we created a set of initiator-target dyads. For each initiator-target dyad we included all potential joiners that met the two conditions that define a politically relevant triad. 
because it did not join either side by the end of the war. Our sample includes 1,274 politically relevant MIDs and 88,916 politically relevant triad years (observations).

We distinguish between joining the initiator and joining the target. As the labeling of the two initial belligerents highlights, different processes are likely to be at work for a third party's decision to join the initiator compared to the target. To the extent that a decision to join the initiator is different from a decision to join the target, our covariates should have a different effect on the risk of joining the initiator compared to the risk of joining the target. For example, a covariate may have a negative effect on the hazard (that is, the risk of joining at a particular time point given that the third party has not already joined) of joining the initiator, but a positive effect on the hazard of joining the target. Since our covariates can potentially have different effects on the risk of joining one side or the other, not distinguishing between joining in general and joining a particular side constrains the covariate effect (that is, it is the same for joining either side). Our politically relevant sample includes 511 cases of joining: 294 on the side of the initiator and 217 on the side of the target. ${ }^{92}$

While each observation in our dataset represents a year in a MID, each third party is at risk of joining on each day of a MID. Most research on conflict expansion uses the year as the temporal unit of observation. However, since approximately 83 per cent of the MIDs in our dataset lasted less than a year, we believe a more fine-grained temporal unit is more appropriate to examine the timing of joining decisions and will provide more nuanced results. ${ }^{93}$ The shortest MID in our dataset lasts for two days, the longest for 4,779 days, and the mean and median duration of MIDs is 235 and 120 days, respectively. In addition, approximately 88 per cent of joining occurs within the first year of a MID, and the mean and median time until joining are 155 and fifty-two days, respectively.

Since we are interested in both the timing and side of third-party joining, we use a competing risks event history model.$^{94}$ For each day in a MID, each third party that is not already participating can choose either to join the initiator or join the target. In the competing risks framework, each of these choices is treated as part of the set of possible decisions available to third parties during a MID. These choices (risks) 'compete' to be the first outcome that is observed in the historical record, such that each third party is at risk of making a transition to one of these two choices, given our set of covariates, for each day during a MID. For example, if a third party joins the initiator, then that joining decision is the first outcome that is observed in the historical record. However, there existed some probability that the third party would join the target up until the point in time at which it joined the initiator. Although the probability that this alternative decision will occur at any point in time might be small, it remains a possibility for which we should account.

To implement the competing risks model, we estimate two separate Cox proportional hazard models: one for the risk of joining the initiator and one for the risk of joining

${ }^{92}$ We lose few joining cases by limiting the set of all potential joiners to those that are politically relevant. We lose fifty-four cases of joining: twenty-four on the initiator and thirty on the target. This suggests that contiguous states and/or major powers account for most of the joining.

${ }_{93}$ In addition, when using the year as the temporal unit, care has to be taken to ensure that independent variables, such as alliances, are actually operative during the MID. For example, when the temporal unit is the year, it is necessary to ensure that an alliance between a third party and an initial belligerent was in effect during the MID and did not end before the MID began or start after the MID ended.

${ }^{94}$ An introduction to competing risk models can be found in Janet M. Box-Steffensmeier and Bradford S. Jones, Event History Modeling (Cambridge: Cambridge University Press, 2004), pp. 166-81. 
the target. ${ }^{95}$ For each model, we treat failure due to the other risk as randomly censored. For example, we estimate a model for the risk of joining the initiator in which we treat failures due to joining the target as randomly censored. The competing risks model makes the assumption that the risks, conditional on our covariates, are independent: if an observation fails due to one risk, it could have failed due to the other if the MID had lasted long enough. Thus the decision to join the initiator is independent of the decision to join the target. In this way, there is a potential failure time associated with each of the risks. ${ }^{96}$

Once an observation fails due to one risk, it exits the sample and is no longer at risk of experiencing failure due to the other risk. In other words, we only observe the first joining instance. For example, in the model we use to estimate the risk of joining the target, if a third party joins the target, then it is no longer at risk of joining the initiator. Thus when Greece joined the Allied Powers in World War I it was no longer at risk of joining the Central Powers. If, by the end of a MID, a third party has not joined one of the sides then it is coded as right-censored (for example, Switzerland in World War I). ${ }^{97}$

We tested for violations of the proportional hazards assumption in each of our Cox models using the scaled Schoenfeld residuals and corrected for non-proportionality by interacting the offending covariates with the natural log of time. ${ }^{98}$ Finally, we cluster by each initiator-target-potential joiner triad within each MID. Thus we assume that there is not independence across triads within the same MID, which is important when there are multiple initiators and/or targets in a MID.

\section{Independent Variables}

Below we present the operationalization for each of our opportunity and willingness variables. Since we estimate two Cox models, one for the risk of joining the initiator and one for the risk of joining the target, each variable is operationalized differently between

${ }^{95}$ We prefer the Cox model to its parametric alternatives because it makes no assumption about the distributional form of the baseline hazard rate (that is, the risk of third-party joining as a MID persists).

${ }^{96}$ If the decision to join the initiator, conditional on the covariates, is not independent from the decision to join the target, then the assumption that we can treat the choices as randomly censored is violated. In this case, a dependent risks model is appropriate. See Sanford C. Gordon, 'Stochastic Dependence in Competing Risks', American Journal of Political Science, 46 (2002), 200-17; Kentaro Fukumoto, 'Systematically Dependent Competing Risks and Strategic Retirement', American Journal of Political Science, 53 (2009), 740-54; Aaron Han and Jerry A. Hausman, 'Flexible Parametric Estimation of Duration and Competing Risk Models', Journal of Applied Econometrics, 5 (1990), 1-28; Daniel H. Hill, William G. Axinn and Arland Thorton, 'Competing Hazards with Shared Unmeasured Risk Factors', Sociological Methodology, 23 (1993), 245-77. However, as far as we know there is no way to directly test whether the risks are independent; we are not aware of any statistical software that can estimate a dependent risks model. We did estimate the discrete-time analog of the competing risks model using a multinomial logit with a control for time dependence, and then tested the independence of the irrelevant alternatives assumption (IIA). Overall, the results suggest that we fail to reject the null hypothesis that the outcomes are independent. We also estimated a multinomial probit model, which does not make the IIA, and its results were similar to those of the multinomial logit model. These two assessments give us additional confidence that we can treat our competing risks as independent.

${ }^{97}$ Event history models can incorporate these censored observations because a third party is at risk of joining at each time point during a MID, and third parties that do not join contribute information to the baseline hazard through the survivor function.

98 Janet M. Box-Steffensmeier and Christopher J.W. Zorn, 'Duration Models and Proportional Hazards in Political Science', American Journal of Political Science, 45 (2001), 972-88. 
the models to reflect our theoretical arguments. We also estimate a model in which we do not differentiate between the two sides and present the operationalization of each variable for this model.

\section{Opportunity Variables}

Capability. We use the COW Composite Index of National Capability (CINC) to measure the capability of the initiator, target and each potential joiner. ${ }^{99}$ We adjust a potential joiner's capability contribution to account for distance (in miles) to the initial belligerents using the loss-of-strength gradient. ${ }^{100}$ Since a potential joiner can either join the initiator or the target, we followed Bueno de Mesquita and discounted a potential joiner's capability contribution to the location where it is stronger. ${ }^{101} \mathrm{We}$ accounted for the fact that some MIDs have multiple initial belligerents by finding the shortest distance between a potential joiner and all of the initial belligerents. We followed the procedures used in Bueno de Mesquita, whose indicator 'depends on the number of days it takes to transport a major military operation'. ${ }^{102}$ Bueno de Mesquita defines the transportation range as 250 miles per day from 1816-1918, 375 miles per day from 1919-1945 and 500 miles per day after $1945 .{ }^{103}$ We then adjusted a potential joiner's CINC score using the formula from Bueno de Mesquita: ${ }^{104}$

$$
\text { Adjusted } \mathrm{CINC}=\mathrm{CINC}^{\left.\log _{10}[\text { (miles/miles per day })+(10-e)\right]}
$$

Our measure accounts for the difference in the probability that an initial belligerent wins if the potential joiner joins that initial belligerent and the probability that the initial belligerent wins if the potential joiner does not join (that is, remains neutral). The capability contribution a potential joiner can make to the initiator is calculated as the capabilities of the initiator and potential joiner relative to the combined capabilities of the initiator, target and potential joiner minus the capabilities of the initiator relative to the initial belligerents:

$$
\frac{C_{I}+C_{P J}}{C_{I}+C_{T}+C_{P J}}-\frac{C_{I}}{C_{I}+C_{T}}
$$

99 J. David Singer, Stuart Bremer and John Stucky, 'Capability Distribution, Uncertainty, and Major Power War, 1820-1965', in Bruce M. Russett, ed., Peace, War, and Numbers (Beverly Hills, C.A.: Sage Publications, 1972), pp. 19-48.

${ }^{100}$ Boulding, Conflict and Defense. Since our temporal domain is 1816-2001 we combined several distance data sets to take advantage of the best dataset available for each time period. For the time period 1816-1874, we used capital-to-capital distance (in miles, generated by EUGene). For the 1875-1945 time period, we used the Gleditsch and Ward minimum distance dataset (converted from km to miles using $1 \mathrm{~km}=0.621371192$ miles) (Gleditsch and Ward 2001). In the Gleditsch and Ward data set, minimum distances are recorded for states within $950 \mathrm{~km}$ (or $\approx 590$ miles). Thus, for states at distances greater than $950 \mathrm{~km}$ from each other we used capital-to-capital distances (generated by EUGene). For the 1946-2001 time period, we used the minimum distance between states (converted from $\mathrm{km}$ to miles) from the CShapes dataset (Weidmann, Kuse and Gleditsch 2010). Kristian S. Gleditsch and Michael D. Ward, 'Measuring Space: A Minimum Distance Database and Applications to International Studies', Journal of Peace Research, 38 (2001), 739-58; Nils B. Weidmann, Doreen Kuse and Kristian Skrede Gleditsch, 'The Geography of the International System: The CShapes Dataset', International Interactions, 36 (2010), 86-106.

101 Bueno de Mesquita, The War Trap, p. 108.

102 Bueno de Mesquita, The War Trap, p. 104.

103 Bueno de Mesquita, The War Trap.

104 Bueno de Mesquita, The War Trap, p. 105. 
where $C_{I}, C_{T}$ and $C_{P J}$ represent the capabilities of the initiator, target and potential joiner, respectively. The term on the left represents the probability that the initiator wins if the potential joiner joins the initiator, and the term on the right represents the probability that the initiator wins if the potential joiner does not join (remains neutral). ${ }^{105} \mathrm{We}$ use this variable in the Join Initiator model. The capability contribution a potential joiner can make to the target is calculated similarly, except that the term on the left now represents the probability that the target wins if the potential joiner joins the target, and the term on the right represents the probability that the target wins if the potential joiner does not join (remains neutral):

$$
\frac{C_{T}+C_{P J}}{C_{I}+C_{T}+C_{P J}}-\frac{C_{T}}{C_{I}+C_{T}} .
$$

We use this variable in the Join Target model. In the Join Either Initiator or Target model (which combines the two risks), we measure the maximum capability contribution a potential joiner could make to either initial belligerent:

$$
\max \left(\frac{C_{I}+C_{P J}}{C_{I}+C_{T}+C_{P J}}-\frac{C_{I}}{C_{I}+C_{T}}, \frac{C_{T}+C_{P J}}{C_{I}+C_{T}+C_{P J}}-\frac{C_{T}}{C_{I}+C_{T}}\right) .
$$

Thus if a potential joiner's capability contribution to the initiator (target) is greater than its capability contribution to the target (initiator), then we use that value to represent the capability contribution a potential joiner could make to either initial belligerent. ${ }^{106}$

Geographic proximity. Geographic proximity is measured by determining whether the potential joiner shares a common land border or is separated by 150 miles or less of water from the initiator or target (that is, contiguous) as determined by the COW Direct Contiguity dataset. ${ }^{107} \mathrm{We}$ created a binary variable that equals 1 if the potential joiner and an initial belligerent are contiguous and 0 otherwise. In the Join Either Initiator or Target model we include a variable that measures whether a potential joiner is contiguous to either the initiator or target. In the Join Initiator model we include a variable that measures whether a potential joiner is contiguous to the target, and in the Join Target model we include a variable that measures whether a potential joiner is contiguous to the initiator.

\section{Willingness Variables}

Regime type. We measured regime similarity between a potential joiner and the initial belligerents using the Polity IV data set. ${ }^{108}$ We computed regime similarity by

\footnotetext{
105 We account for the fact that some MIDs have multiple initial belligerents by summing the CINC scores of the initial belligerents on each side.

${ }^{106}$ In all of these operationalizations, if a MID lasts past December 31 of a given year, then a state's CINC score can change, which means that a potential joiner's capability contribution to an initial belligerent can change as well.

107 Douglas Stinnett, Jaroslav Tir, Philip Schafer, Paul F. Diehl and Charles Gochman, 'The Correlates of War Project Contiguity Data, Version 3', Conflict Management and Peace Science, 19 (2002), 58-66.

108 Monty G. Marshall and Keith Jaggers, Polity IV Project: Political Regime Characteristics and Transitions, 1800-2002. Dataset Users' Manual (College Park, Md.: Center for International Development and Conflict Management, 2002).
} 
calculating the difference between a state's democracy and autocracy scores, which range from -10 to +10 , to which we add 10 , so that the scores range from 0 to 20 (higher values indicate more democratic). States with scores between 16 and 20 (inclusive) are coded as democracies, and states with scores between 0 and 4 (inclusive) are coded as autocracies. We create two binary variables, one that equals 1 if a potential joiner and an initial belligerent are democracies and 0 otherwise, and one that equals 1 if a potential joiner and an initial belligerent are both autocracies and 0 otherwise. In the Join Either Initiator or Target model we include two variables: whether a potential joiner and the initiator or target are democratic, and whether a potential joiner and the initiator or target are autocratic. In the Join Initiator model we include two variables: whether a potential joiner and the initiator are both democratic, and whether a potential joiner and the initiator are both autocratic. In the Join Target model we include two variables: whether a potential joiner and the target are both democratic, and whether a potential joiner and the target are both autocratic.

676

677

678

679

680

681

682

683

684

685

686

687

688

689

Alliance. We measured whether a potential joiner had an alliance obligation with an initial belligerent using the Alliance Treaty Obligations and Provisions (ATOP) dataset. ${ }^{109}$ The ATOP dataset provides the precise obligations undertaken by each member of an alliance. We examined three types of alliance obligations: defence, offence and neutrality. Defence and offence pacts obligate a member of an alliance to provide military assistance in the event of military conflict involving another member of the alliance, and neutrality pacts involve an explicit promise not to join a conflict against an ally and not to facilitate an adversary's success in the event of a conflict with the ally.

Since two states that are part of the same alliance do not necessarily undertake symmetric obligations, we coded the obligation of the potential joiner to the initiator or target of a MID and not vice-versa. In order for a potential joiner and an initial belligerent to be coded as having an alliance obligation, the alliance had to be in effect for the full duration of a MID. If an alliance between a potential joiner and an initial belligerent was signed or terminated during a MID, then the obligation is not coded as being in effect. If an initial belligerent and a potential joiner were involved in multiple alliances, we coded the presence of an alliance obligation if at least one of the obligations was in effect for the full duration of a MID.

We included three binary variables for defensive, offensive and neutrality obligations. Each binary variable equals 1 if a potential joiner and an initial belligerent had a defensive, offensive or neutrality obligation, respectively, and 0 otherwise. In the Join Either Initiator or Target model we include three variables: (1) whether a potential joiner had a defence pact with the initiator or target, (2) whether a potential joiner had an offence pact with the initiator or target and (3) whether a potential joiner had a neutrality pact with the initiator or target. In the Join Initiator model we include three variables: (1) whether a potential joiner had a defence pact with the initiator, (2) whether a potential joiner had an offence pact with the initiator and (3) whether a potential joiner had a neutrality pact with the initiator. In the Join Target model we include three variables: (1) whether a potential joiner had a defence pact with the target, (2) whether a potential joiner had an offence pact with the target and (3) whether a potential joiner had a neutrality pact with the target.

109 Leeds et al., 'Alliance Treaty Obligations and Provisions'.
690

691

692

693

694

695

696

697

698

699

700

701

702

703

704

705

706

707

708

709

710

711

712

713

714

715

716

717 
Rivalry. We measured whether a potential joiner had a rivalry with an initial belligerent using Thompson's operationalization of rivalry. ${ }^{110} \mathrm{We}$ created a binary variable that equals 1 if a potential joiner and an initial belligerent are strategic rivals, and 0 otherwise. In the Join Either Initiator or Target model we included a variable that measures whether a potential joiner is a strategic rival of the initiator or target. In the Join Initiator model we include a variable that measures whether a potential joiner is a strategic rival of the target. In the Join Target model we included a variable that measures whether a potential joiner is a strategic rival of the initiator.

Previous major power joining. We measured the joining of a major power using a binary variable that recorded whether or not a major power joined a MID. Major powers are determined using the COW State System Membership List. ${ }^{111}$ Since each observation in our dataset represents a year in a MID, we coded the first major power that joined a MID as not being affected by the joining of a previous major power. However, all other potential joiners' decisions were coded as being affected by the prior joining of a major power. If a non-major power joined a MID, then all other potential joiners' decisions are coded as not being affected by the prior joining of a major power. In the Join Either Initiator or Target model we included a variable that measures whether or not a major power joined the initiator or target. In the Join Initiator model we included a variable that measures whether or not a major power joined the initiator. In the Join Target model we included a variable that measures whether or not a major power joined the target.

\section{RESULTS}

In order to demonstrate the importance of differentiating between joining in general and joining the initiator or the target, we estimated a model in which we pooled the risks. The results are in the first column of Table 1. The results for the pooled model represent the 'average' effect of a covariate on the risk of joining either the initiator or the target. In columns two and three of Table 1, we present the results from the competing risks model. The second column presents the results for joining the initiator and the third presents the results for joining the target. A positive (negative) coefficient indicates that the covariate increases (decreases) the risk of joining and that the time until joining occurs decreases (increases). ${ }^{112}$

Across all three models, as a third party's capability contribution to an initial belligerent increases the risk that a third party will join an ongoing MID increases, although this effect differs between joining the initiator and joining the target. This initially positive effect subsequently decreases. In Figure 1, we plot the effect of capability on the risk of a third party joining during an ongoing MID. In this figure, the y-axis represents the percentage change in the hazard ratio (the difference in the risk of joining for different values of capability) and the $\mathrm{x}$-axis represents time measured in days. ${ }^{113}$ Panel A shows the median

110 William R. Thompson, 'Identifying Rivals and Rivalries in World Politics'.

111 Correlates of War Project State System Membership List.

112 We also estimated these models on three additional samples: (1) all triads, (2) all triads without World Wars I and II and 3) politically relevant triads without World Wars I and II. We note the differences in the results for our risk specific models in the politically relevant triads sample and the three other samples.

${ }^{113}$ Figures 1 and 2 were generated using the procedures presented in Amanda A. Licht, 'Change Comes with Time: Substantive Interpretation of Nonproportional Hazards in Event History Analysis', Political Analysis, 19 (2011), 227-43. 
TABLE 1 Competing Risks Model of Third-Party Joining, 1816-2001: Politically Relevant Triads

\begin{tabular}{|c|c|c|c|}
\hline & $\begin{array}{l}\text { Join Either Initiator } \\
\text { or Target }\end{array}$ & $\begin{array}{l}\text { Join } \\
\text { Initiator }\end{array}$ & $\begin{array}{l}\text { Join } \\
\text { Target }\end{array}$ \\
\hline \multirow[t]{2}{*}{ Capability } & $6.86^{\star}$ & $2.11^{\dagger}$ & $8.69^{*}$ \\
\hline & 0.64 & 1.02 & 0.81 \\
\hline \multirow[t]{2}{*}{ Capability $\times$ Ln (time) } & $-1.01^{*}$ & -0.27 & $-1.16^{*}$ \\
\hline & 0.14 & 0.22 & 0.17 \\
\hline \multirow[t]{2}{*}{ Geographic proximity } & $3.55^{\star}$ & $4.12^{*}$ & $2.53^{\star}$ \\
\hline & 0.56 & 0.68 & 0.67 \\
\hline \multirow[t]{2}{*}{ Geographic proximity $\times$ Ln (time) } & -0.54 & $-0.60^{*}$ & $-0.46^{\ddagger}$ \\
\hline & 0.10 & 0.13 & 0.13 \\
\hline \multirow[t]{2}{*}{ Democracy } & $3.06^{*}$ & $6.87^{*}$ & -0.79 \\
\hline & 0.59 & 0.95 & 0.86 \\
\hline \multirow[t]{2}{*}{ Democracy $\times$ Ln (time) } & -0.64 & $-1.34^{*}$ & 0.19 \\
\hline & 0.11 & 0.19 & 0.17 \\
\hline \multirow[t]{2}{*}{ Autocracy } & $1.78^{*}$ & $3.74^{*}$ & -0.16 \\
\hline & 0.56 & 0.93 & 0.51 \\
\hline \multirow[t]{2}{*}{ Autocracy $\times$ Ln (time) } & $-0.37^{*}$ & $-0.70^{*}$ & 0.06 \\
\hline & 0.11 & 0.18 & 0.10 \\
\hline \multirow{2}{*}{ Defence pact } & $2.30^{*}$ & $2.23^{\star}$ & $3.96^{\star}$ \\
\hline & 0.42 & 0.53 & 0.71 \\
\hline \multirow[t]{2}{*}{ Defence pact $\times$ Ln (time) } & $-0.29^{*}$ & -0.16 & $-0.63^{*}$ \\
\hline & 0.08 & 0.10 & 0.14 \\
\hline \multirow[t]{2}{*}{ Offence pact } & 0.27 & 0.11 & $1.61^{\dagger}$ \\
\hline & 0.21 & 0.32 & 0.38 \\
\hline \multirow[t]{2}{*}{ Neutrality pact } & 0.40 & $1.75^{*}$ & 0.60 \\
\hline & 0.25 & 0.26 & 0.47 \\
\hline \multirow[t]{2}{*}{ Rivalry } & $0.94^{*}$ & $1.28^{*}$ & $1.31^{*}$ \\
\hline & 0.13 & 0.20 & 0.22 \\
\hline \multirow[t]{2}{*}{ Previous major power joining } & $1.90^{*}$ & 0.33 & $4.97^{+}$ \\
\hline & 0.47 & 1.24 & 0.67 \\
\hline \multirow{2}{*}{$\begin{array}{l}\text { Previous major power joining } \times \text { Ln } \\
\quad \text { (time) }\end{array}$} & -0.11 & 0.18 & $-0.61^{*}$ \\
\hline & 0.09 & 0.22 & 0.13 \\
\hline No. of observations & 88,916 & 88,916 & 88,916 \\
\hline No. of joining cases & 511 & 294 & 217 \\
\hline Time at risk & $13,048,024$ & $13,048,024$ & $13,048,024$ \\
\hline Log-likelihood & -4518.52 & -2538.17 & -1879.05 \\
\hline Wald $\chi_{(15,15,15)}^{2}$ & $1348.18^{\ddagger}$ & $1064.59^{\ddagger}$ & $719.12^{\ddagger}$ \\
\hline
\end{tabular}

Significance levels (two-tailed): $† 5 \% ; \ddagger 1 \%$.

Coefficients with robust standard errors below.

percentage change in the hazard of joining when a third party's capability increases from the first to the second quartile, while Panel B illustrates the median percentage change when a third party's capability increases from the second to the third quartile. ${ }^{114}$

114 Formally, the percentage change in the hazard ratio is: $\% \Delta \mathrm{h}_{\mathrm{i}}(\mathrm{t})=\left(e^{\left(\mathrm{X}_{\mathrm{i}}-\mathrm{X}_{\mathrm{j}}\right)\left(\beta_{1}+\beta_{2} \ln (\mathrm{t})\right)}-1\right) \times 100$. See Licht (2011). The summary statistics reveal that the capability variable is skewed, with most values clustering near zero. As a result, a percentage change in the hazard ratio that is calculated, for example, using the mean value and one standard deviation above the mean value, is not meaningful because the percentage of third parties that have that value of capability is quite small. For example, in the Join Either Initiator or Target model, one standard deviation above the mean is 0.28 , and only 12 per cent of potential joiners have a value above 

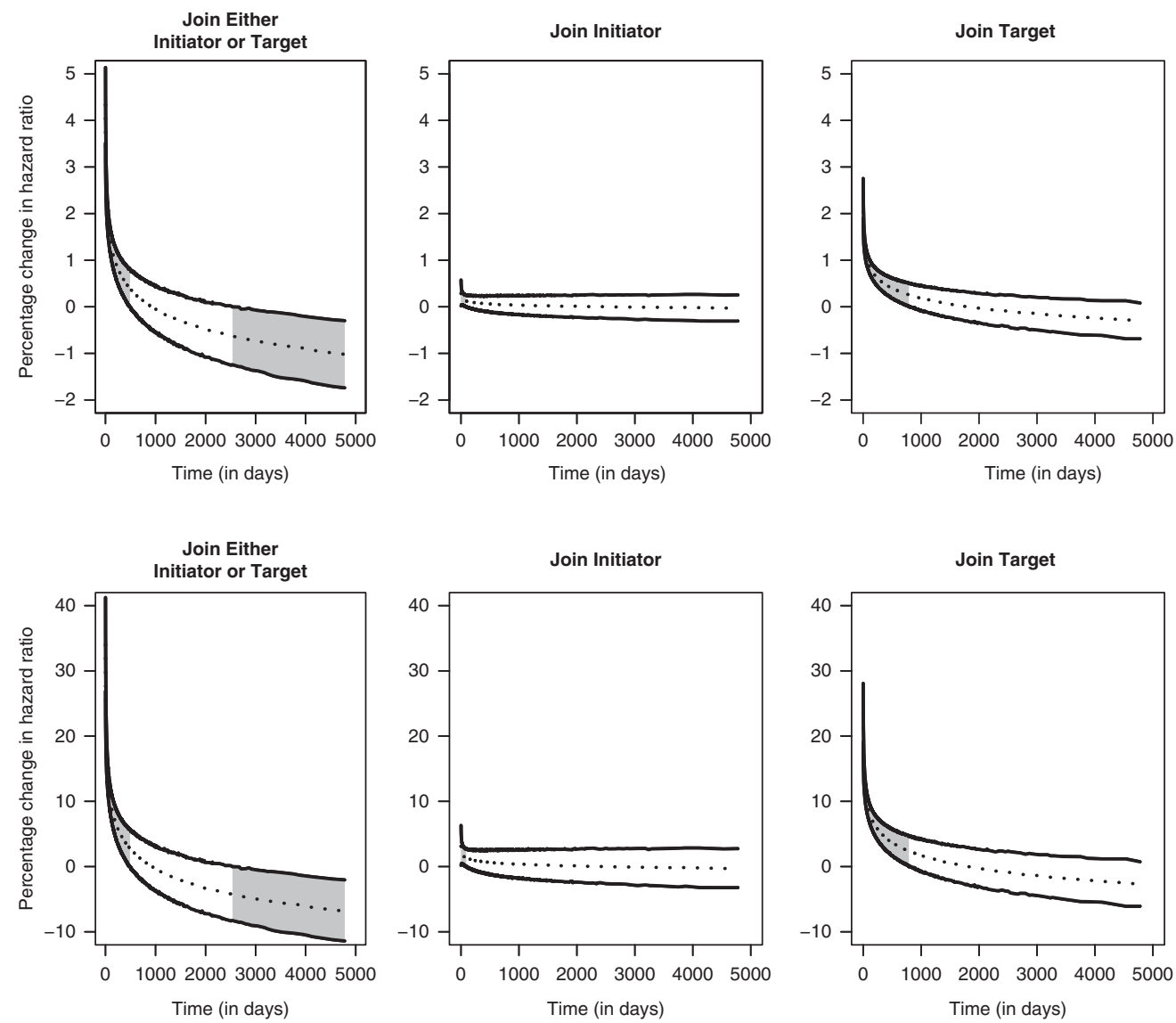

Fig. 1. Effect of capability on the risk of a third party joining during an ongoing MID

Note: The dashed line displays the median percentage change in the hazard of joining when a third party's capability increases from the first to the second quartile (Panel A) and from the second to the third quartile (Panel B), while the solid lines correspond to the 95 per cent confidence interval. An area that is shaded grey indicates that the variable's effect is statistically significant, while an area that is white indicates that the variable's effect is not statistically significant. Y-axis scales differ across panels.

(F'note continued)

that number. Additionally, one standard deviation below the mean is -0.1 , which is nonsensical since a third party's capability contribution is always greater than zero. Thus in order to calculate the substantive effect of capability on the risk of joining we used the first, second and third quartiles. In the Join Either Initiator or Target model, the value that cuts off the first quartile is 0.001 , the value that cuts off the second (or median) quartile is 0.007 and the value that cuts off the third quartile is 0.05 . Therefore we calculate the percentage change in the hazard ratio if a third party's capability increases from the first to the second quartile (an increase of 0.006) and from the second to the third quartile (an increase of 0.043). In the Join Initiator model, the value that cuts off the first quartile is 0.0001 , the value that cuts off the second quartile is 0.0015 and the value that cuts off the third quartile is 0.016 . An increase in a third party's capability from the first to the second quartile is 0.0014 and from the second to the third quartile is 0.015 . In the Join Target model, the value that cuts off the first quartile is 0.0002 , the value that cuts off the second quartile is 0.003 and the value that cuts off the third quartile is 0.03 . An increase in a third party's capability from the first to the second quartile is 0.003 and from the second to the third quartile is 0.027 . 
In the Join Either Initiator or Target model, an increase in a third party's capability from the first to the second quartile produces an initial 5 per cent increase in the risk of joining. However, this initial increase subsequently decreases and is not statistically significant between days 487 and 2,507 of a MID. While this effect becomes negative and significant after day 2,507, there are no joining cases after this point in time. In the Join Initiator model an increase in a third party's capability from the first to the second quartile produces a very small (less than 1 per cent) increase in the risk of joining. This small effect is only significant until day 89 of a MID. While this effect is only statistically significant for a short period of time, approximately 60 per cent of joining cases on the initiator side occur while the effect is positive and significant. There is a larger increase in the risk of a third party joining the target as its capability increases from the first to the second quartile, but this effect is still quite small (only about 3 per cent). The initial increase in the risk of joining the target subsequently decreases and is statistically significant for a much longer time period: the first 820 days of a MID. In contrast to joining the initiator, the effect for joining the target is positive and significant for 98 per cent of the cases in which a third party joined the target.

When a third party's capability contribution increases from the second to the third quartile, the statistical significance follows the same pattern of results. However the substantive effect of this increase is much larger, as indicated by the different y-axis scale. In the Join Either Initiator or Target model, an increase from the second to the third quartile produces a 40 per cent (as opposed to 5 per cent) increase in the risk of joining. The increase in the risk of joining the initiator is small compared to joining the target, where the increase in the risk of joining is nearly 30 per cent (as opposed to 3 per cent). ${ }^{115}$

These results are consistent with our expectations. As the capability contribution a third party can make to an initial belligerent increases, the likelihood of joining also increases. This result is similar to the findings in the extant literature. ${ }^{116}$ Additionally, if initiators target weak states, then our results lend support to the notion that third parties join the target in an attempt to balance against a more powerful initiator. This finding supports Walt's notion that 'states that are viewed as aggressive are likely to provoke others to balance against them'. ${ }^{117}$ These results are also consistent with the arguments of Waltz and previous empirical research that finds balancing to be more prevalent than bandwagoning. ${ }^{18}$

Across all three models, geographic proximity to an initial belligerent initially increases the risk that a third party will join an ongoing MID relative to non-proximate third parties. However, this initially positive effect quickly becomes negative, and thus decreases the risk that a geographically proximate third party will join an ongoing MID. However, the point in time when this effect changes from positive to negative differs across the models. When we do not differentiate between joining the initiator and joining the target, the effect changes

\footnotetext{
115 In the Join Initiator model, the initial effect of capability is positive in all four samples but is only statistically significant in the politically relevant triads sample with World Wars I and II. The effect of capability does not significantly decrease over time in any of the samples except the all triads sample without the world wars, in which the effect increases over time but not significantly. In the Join Target model, the effect of capability is initially positive and statistically significant, and significantly decreases over time in all four samples.

116 Altfeld and Bueno de Mesquita, 'Choosing Sides in Wars'; Bremer, 'National Capabilities and War Proneness'; Huth, Extended Deterrence.

117 Walt, The Origins of Alliances, p. 25.

118 Waltz, Theory of International Politics; Melin and Koch, 'Jumping into the Fray'.
} 
from positive to negative after day 737 of a MID. However for joining the initiator this effect changes on day 930, and for joining the target the effect changes on day 253. Thus geographic proximity to the target increases the risk that a third party will join the initiator for a longer period of time than geographic proximity to the initiator does for joining the target. Interestingly, the effect is not significant between days 441 and 4,170 for joining the initiator and days 102 to 1,242 for joining the target. Thus for approximately 92 per cent of the joining cases on the initiator side, the effect of geographic proximity is positive and significant, while 0 per cent had a negative and significant effect. For joining the target, 69 per cent of the cases have a positive and significant effect while 1 per cent have a negative and significant effect. ${ }^{119}$

Overall, these results suggest that geographic proximity strongly increases the risk that a third party will join early in a MID, and that a third party geographically proximate to the target is more likely to join the initiator sooner than a third party geographically proximate to the initiator will join the target. In Table 2 we present the percentage change in the hazard ratio for each binary independent variable that violated the proportional hazards assumption at different points in time during a MID. ${ }^{120}$ The risk that a third party that is geographically close to the target will join the initiator initially increases by 6,035 per cent relative to a non-proximate third party and decreases to 308 per cent within the first three months of a MID. In contrast, the risk that a third party that is geographically close to the initiator will join the target decreases from 1,155 per cent to 60 per cent over the same time period. While the results for geographic proximity are consistent with those of Siverson and Starr and others who have shown that contiguity influences joining decisions, our results add to the existing research by showing how contiguity influences when third parties join. ${ }^{121}$

Of particular interest are the findings for democracy, since there is much written about its influence on joining in the extant literature. In Figure 2 (Panel A), we plot the effect of democracy on the risk of a third party joining an ongoing MID. In this figure, the y-axis represents the combined coefficient, which 'describes the direction and magnitude of the variable's effect on the hazard rate over time', and the x-axis represents time measured in days. ${ }^{122}$ These results highlight the importance of distinguishing between joining the initiator and joining the target. In the Join Either Initiator or Target model, democratic similarity with at least one initial belligerent initially increases the risk of a third party joining; however, this effect becomes negative after day 120. A similar pattern is observed in the Join Initiator model, in which the initially positive effect becomes negative after day 170. Approximately 65 per cent of cases in which a third party joined the initiator occurred when the effect was positive and significant, compared to 18 per cent when the effect was negative and significant. In contrast, in the Join Target model, after day 61 the initially negative effect on the risk of joining becomes positive. However, in neither

\footnotetext{
119 In both the Join Initiator and Join Target models, the initial effect of geographic proximity is positive and statistically significant, and significantly decreases over time in all four samples except the politically relevant triads samples without the world wars. In the politically relevant triads sample without the world wars, the effect of geographic proximity is positive and statistically significant but does not change over time in either the Join Initiator or the Join Target model.

${ }_{120}$ The formula for the percentage change in the hazard ratio is the same as for continuous variables (see fn. 114), where $X_{i}=1$ and $X_{j}=0$.

${ }^{121}$ Siverson and Starr, The Diffusion of War; see also Melin and Koch, 'Jumping into the Fray'.

${ }^{122}$ Licht, 'Change Comes with Time', p. 232. Formally, the combined coefficient is: $\beta_{\text {constitutive }}+$ $\left.\left(\beta_{\text {constitutive }} \times \ln (\mathrm{t})\right)\right)$.
} 
TABLE 2 Percentage Change in Hazard Ratio for Binary Independent Variables that Violated the Proportional Hazards Assumption at Different Time Points During a MID

\begin{tabular}{|c|c|c|c|c|c|c|c|c|c|c|c|c|c|c|}
\hline & \multirow[b]{2}{*}{ Model } & \multicolumn{13}{|c|}{ Days } \\
\hline & & 1 & 10 & 30 & 60 & 90 & 120 & 150 & 180 & 365 & 729 & 1,095 & 1,458 & 1,821 \\
\hline \multirow[t]{3}{*}{ Geographic proximity } & Pooled & 3,392 & 911 & 460 & 286 & 210 & 166 & 136 & 114 & 46 & 1 & -19 & -31 & -39 \\
\hline & Initiator & 6,035 & 1,433 & 691 & 421 & 308 & 243 & 200 & 169 & 76 & 16 & -9 & -24 & -33 \\
\hline & Target & 1,155 & 338 & 165 & 93 & 60 & 41 & 27 & 17 & -15 & -38 & -49 & -55 & -59 \\
\hline \multirow[t]{3}{*}{ Democracy } & Pooled & 2,037 & 390 & 142 & 56 & 20 & 0 & -13 & -23 & -51 & -69 & -76 & -80 & -82 \\
\hline & Initiator & 96,332 & 4,323 & 916 & 302 & 134 & 59 & 18 & -8 & -64 & -86 & -92 & -94 & -96 \\
\hline & Target & -55 & -29 & -13 & 0 & 8 & 14 & 19 & 23 & 41 & 61 & 74 & 84 & 92 \\
\hline \multirow[t]{3}{*}{ Autocracy } & Pooled & 493 & 151 & 67 & 29 & 11 & -1 & -9 & -15 & -34 & -49 & -56 & -61 & -64 \\
\hline & Initiator & 4,107 & 737 & 287 & 138 & 79 & 46 & 25 & 10 & -33 & -59 & -69 & -75 & -78 \\
\hline & Target & -15 & -2 & 5 & 9 & 12 & 14 & 15 & 17 & 22 & 27 & 30 & 32 & 34 \\
\hline \multirow{3}{*}{ Defence pact } & Pooled & 898 & 410 & 270 & 202 & 169 & 147 & 131 & 119 & 79 & 46 & 30 & 19 & 12 \\
\hline & Initiator & 829 & 550 & 449 & 393 & 363 & 343 & 328 & 316 & 273 & 235 & 214 & 201 & 190 \\
\hline & Target & 5,152 & 1,139 & 522 & 303 & 212 & 161 & 127 & 102 & 30 & -16 & -35 & -46 & -53 \\
\hline \multirow{3}{*}{$\begin{array}{l}\text { Previous major } \\
\text { power joining }\end{array}$} & Pooled & 567 & 416 & 357 & 323 & 304 & 291 & 282 & 274 & 246 & 220 & 206 & 196 & 189 \\
\hline & Initiator & & 113 & 160 & 195 & 218 & 236 & 250 & 262 & 312 & 368 & 404 & 431 & 453 \\
\hline & Target & 14,327 & 3,483 & 1,744 & 1,112 & 849 & 697 & 596 & 524 & 307 & 168 & 109 & 76 & 54 \\
\hline
\end{tabular}

Note: Numbers in bold indicate that the percentage change in the hazard ratio is statistically significant at the 95 per cent level. 

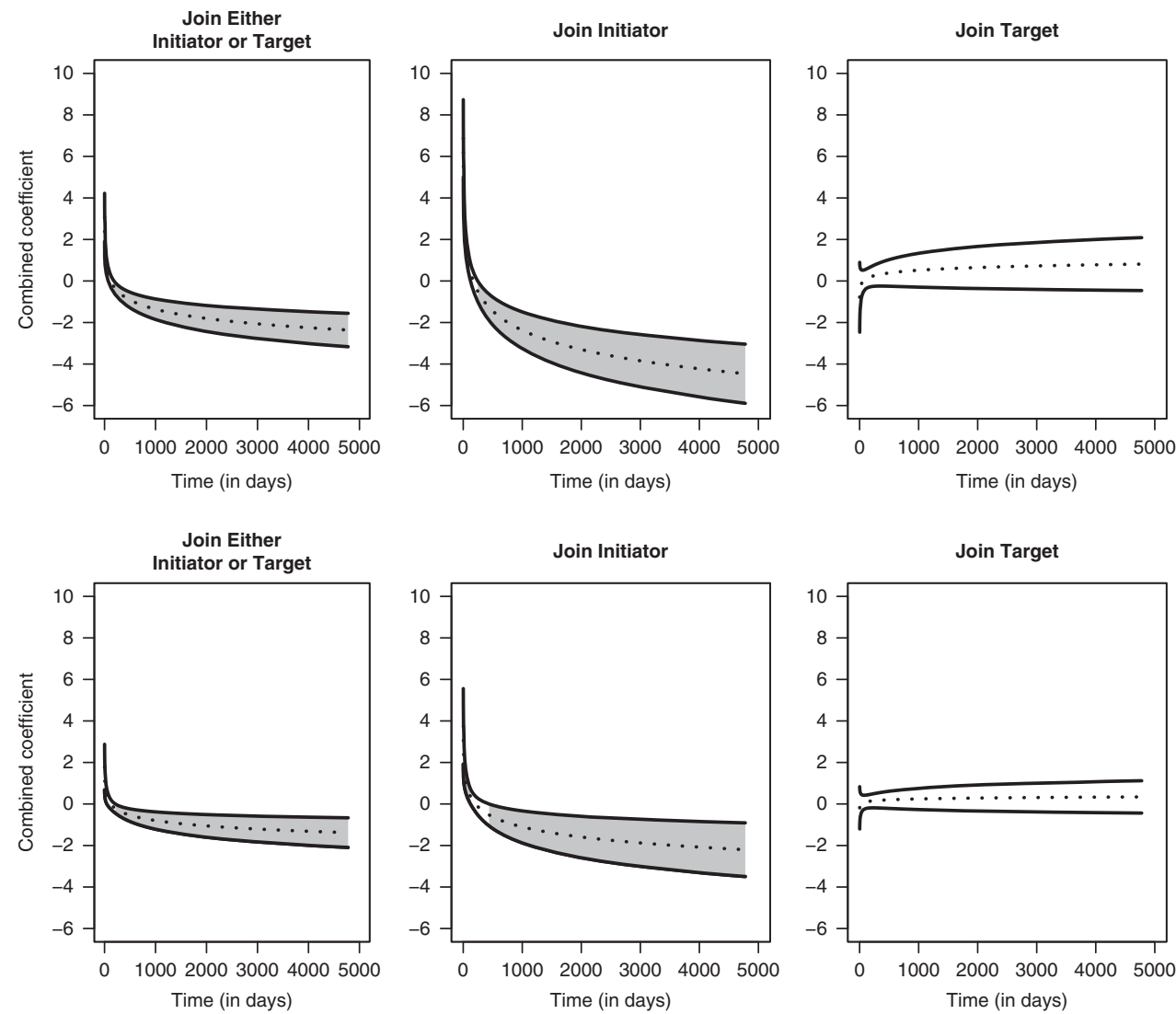

Fig. 2. Effect of democracy (Panel A) and autocracy (Panel B) on the risk of a third party joining during an ongoing MID

Note: The dashed line displays the combined coefficient, while the solid lines correspond to the 95 per cent confidence interval. An area that is shaded grey indicates that the variable's effect is statistically significant, while an area that is white indicates that the variable's effect is not statistically significant.

case does democratic similarity significantly influence the risk of a third party joining the target.

Overall, these results suggest that if a third party and an initiator are both democratic, the risk of joining the initiator increases early in a dispute (within the first six months). This finding is consistent with our expectations and the results of Raknerud and Hegre and Werner and Lemke. ${ }^{123}$ However, the risk of a democratic third party joining a democratic initiator decreases as a dispute persists. The initial risk of a democratic third party joining a democratic initiator initially increases by 96,332 per cent, but decreases to 59 per cent in the first four months of a MID. However, the risk of a democratic third party joining a democratic initiator decreases by 64 per cent after the first year of a MID and continues to decrease as a MID persists. The results for joining the target suggest a very different dynamic. If a third party and a target are both democratic, there is no

${ }^{123}$ Raknerud and Hegre, 'The Hazard of War'; Werner and Lemke, 'Opposites Do Not Attract'. 
statistically significant chance that the third party will join the target at any point during a MID. While this result is consistent with the findings of Mousseau and Reiter and Stam, it is inconsistent with the arguments and findings in Lake and Choi. ${ }^{124}$ By distinguishing between the initial belligerents, these results demonstrate the influence of democracy on when and which side third parties join to an extent that previous research could not.

Figure 2 (Panel B) plots the effect of autocracy on the risk of a third party joining an ongoing MID. As with the results for democracy, these results highlight the importance of distinguishing between joining the initiator and joining the target. In the Join Either Initiator or Target model, autocratic similarity with at least one initial belligerent initially increases the risk of a third party joining; however, this effect becomes negative after day 118. A similar pattern is observed in the Join Initiator model, in which the initially positive effect becomes negative after day 207. Approximately 65 per cent of joining cases have a positive and significant effect of joining the initiator, while 9 per cent have a negative and significant effect. In contrast, in the Join Target model, after day 14 the initially negative effect on the risk of joining becomes positive. However, in neither case does autocratic similarity significantly influence the risk of joining the target. ${ }^{125}$

Overall, these results suggest that if a third party and an initiator are both autocratic, the risk that a third party will join the initiator increases early in a dispute but decreases as a dispute persists. The initial risk of an autocratic third party joining an autocratic initiator initially increases by 4,107 per cent, but decreases to 46 per cent in the first four months of a MID. However, the risk of an autocratic third party joining an autocratic initiator decreases by 59 per cent after the second year of a MID and continues to decrease the longer the MID lasts. In contrast, if a third party and a target are both autocratic, there is no statistically significant chance that the third party will join the target at any point during a MID. These results are consistent with our expectations as well as the findings of Raknerud and Hegre and Corbetta, but question the extent to which autocracies behave differently from democracies. ${ }^{126}$ Interestingly, the results for autocracy are similar to the results for democracy, suggesting that if initiators target weak states then both democratic and autocratic third parties are not likely to come to the aid of targets that share regime similarity. While this result raises doubts about the extent to which any regime type will aid the target of a MID, the risk of a democratic third party joining a democratic initiator is always higher than an autocratic third party joining an autocratic initiator within the first four months of a MID, although the differences between the two regime types decrease over this time period.

Across all three models, having a defence pact with an initial belligerent initially increases the risk that a third party will join an ongoing MID. However, this initially positive effect becomes negative, and thus decreases the risk that a third party will join.

\footnotetext{
${ }^{124}$ Mousseau, Peace in Anarchy; Reiter and Stam, Democracies at War; Lake, 'Powerful Pacifists'; Choi, 'Democratic Synergy'.

${ }^{125}$ In the Join Initiator model, the initial effect of autocracy is positive and statistically significant, and significantly decreases over time in all four samples. In the Join Target model, the initial effect of autocracy is negative and not statistically significant in both samples with the world wars, but positive in both samples without the world wars. However, the effect of autocracy is not statistically significant in any of the samples. The initial effect of autocracy increases over time but is not significant in any of the samples except the politically relevant triads sample without the world wars, in which the effect is negative but not significant.

${ }^{126}$ Raknerud and Hegre, 'The Hazard of War'; Corbetta, 'Determinants of Third Parties' Intervention and Alignment Choices'; Werner and Lemke, 'Opposites Do Not Attract'.
} 
When this effect changes differs across the models. In the Join Either Initiator or Target model, the effect changes from positive to negative on day 2,662 of a MID; however, for joining the target this effect changes on day 553. In contrast, the effect is always positive for joining the initiator. Thus all of the cases of joining the initiator occur when the effect of the defence pact is positive and significant. The effect of a defence pact is not significant for joining the target between days 246 and 2,900 of a MID. Approximately 83 per cent of joining cases occur when the effect is positive and significant, while 0 per cent occur when the effect is negative and significant.

Overall, these results suggest that a defence pact between a third party and the initiator strongly increases the risk that a third party will join the initiator at any point during a MID. While defence pacts are generally designed to aid the target of aggression, a third party that has a defence pact with a target is only significantly likely to aid the target relatively early in a MID (within eight months). Indeed, the risk of joining the target is initially 5,152 per cent higher for a third party with a defence pact with the target than a third party without one. Comparatively, the initial risk that a third party will join the initiator is 829 per cent higher for a third party that has a defence pact with the initiator. While the percentage increase in the risk of joining the target decreases to 522 per cent by the end of the first month of a MID, the percentage increase in the risk of joining for a third party that has a defence pact with the target is still higher than the percentage increase in the risk of joining for a third party that has a defence pact with the initiator. After the first month of a MID, the percentage increase in the risk of joining for a third party with a defence pact with the initiator is higher than the risk of joining for a third party with a defence pact with the target.

The results for offensive alliance obligations suggest that third parties that have an offence pact with a target are likely to honour their alliance commitment. One possibility is that the initiator starts a conflict because it fears an attack is pending. Another possibility is that since offensive pacts suggest a similarity of foreign policy, a third party might decide to join a target in order to maintain its support. Moreover, the exact differences between defence and offence pacts can be 'blurry'. ${ }^{127}$ In contrast, third parties that have an offence pact with an initiator are not likely to honour their alliance commitment, which is contrary to our expectation.

Third parties that have a neutrality pact with an initiator are likely to join the initiator, but third parties that have a neutrality pact with the target are not likely to join the target. Existing conflict expansion research has primarily examined non-aggression pacts, which were found to increase the time until joining, decrease the time until joining the initiator and not influence the time until joining the target. ${ }^{128}$ The ATOP dataset treats nonaggression pacts as distinct from neutrality pacts. ${ }^{129}$

While the results for defence pacts are consistent with existing research, we can provide some additional insight, namely that if a dispute lasts longer than eight months then third parties that have a defence pact with the target are not likely to honour their alliance commitment. ${ }^{130}$ Moreover, our results show that of the three alliance types, defence pacts have the greatest influence, which supports the argument made by Siverson and Starr but

${ }^{127}$ Leeds et al., 'Alliance Treaty Obligations and Provisions', p. 240.

128 Siverson and Starr, The Diffusion of War; Melin and Koch, 'Jumping into the Fray'.

129 Leeds et al., 'Alliance Treaty Obligations and Provisions'.

130 Corbetta, 'Determinants of Third Parties' Intervention and Alignment Choices'; Leeds, 'Alliance Reliability in Times of War'; Leeds, 'Do Alliances Deter Aggression?'; Smith, 'To Intervene or Not to Intervene'. 
for which they had not found empirical support. ${ }^{131}$ At the same time, arguments that allies do not honour their commitments also receive some support, as we find that if a third party with a defence pact does not join the target early in a dispute, it is unlikely to join later. These results help reconcile past discrepant findings by showing that allies do honour their defence pacts with initiators, but only honour their defence pacts with targets relatively early in a dispute. While offence and neutrality pacts are relatively rare compared to defence pacts, the findings for offence and neutrality pacts suggest that the reliability of alliance commitments varies by alliance type.

There has been increasing attention to the effects of rivalry on conflict behaviour in the conflict literature, but little attention has been paid to the role of rivalries in conflict expansion. This is surprising, since the perception of a serious threat has been previously discussed as a central element of joining decisions. Our findings demonstrate that a dispute is particularly likely to draw in additional states if a third party has a rivalry with one of the initial belligerents. Third parties that have a rivalry with the target are more likely to join the initiator, while third parties that have a rivalry with the initiator are more likely to join the target. Thus a third party that has a rivalry with an initial belligerent is at risk of joining the side opposite its rival. These results suggest that third parties that have a rivalry with one of the initial belligerents may use the dispute to inflict additional damage on a rival by joining the rival's opponent. This finding is consistent with what would be expected from the rivalry literature. ${ }^{132}$ These findings also contribute to the balancing and bandwagoning debate, since rivals join the side opposite their rival, which suggests that third parties are concerned about their rivals improving their position. ${ }^{133}$

The results for previous major power joining also highlight the importance of distinguishing between joining the initiator and joining the target. In the Join Either Initiator or Target model, a major power joining with the initiator or target always significantly increases the risk of a third party joining an ongoing MID, although this positive effect decreases over time. In the Join Initiator model, the effect of a major power joining on the initiator side also always increases the risk of joining, although the positive effect increases after day 6 of a MID. However, the effect is positive and significant only after day 30. Approximately 55 per cent of joining cases occur when the effect is positive and significant, while 45 per cent occur when the effect is still positive but not significant (between days 1 and 30). Note that while the constitutive term coefficient is not statistically significant, this only provides the effect of a major power joining on day 1 of a MID. In contrast, in the Join Target model, the effect of a major power joining on the target side changes from positive to negative after day 3,712. Approximately 99 per cent of the

${ }^{131}$ Siverson and Starr, The Diffusion of War.

132 Diehl and Goertz, War and Peace in International Rivalry.

${ }^{133}$ Haldi, Why Wars Widen. In the Join Initiator model, the initial effect of rivalry is positive and statistically significant in all four samples. However, the effect of rivalry significantly decreases over time in all of the samples except the politically relevant triads sample that includes World Wars I and II. Since rivalry did not violate the proportional hazards assumption in that sample, we did not include an interaction with the natural log of time. In the Join Target model, the effect of rivalry is positive and statistically significant in both politically relevant triads samples, but is positive and not statistically significant in both 'all triads' samples. In addition, the effect of rivalry changes inconsistently over time across the four samples; it is positive in the all triads sample, positive and significant in the all triads sample without the world wars, was not included in the politically relevant triads sample without the world wars (because it did not violate the proportional hazards assumption), and is negative and not significant in the politically relevant triads sample without the world wars. 
joining cases occur when the effect of a major power joining is positive and significant, while 0 per cent of the cases occur when the effect is negative and significant. ${ }^{134}$

Overall, these results suggest that a major power joining on the initiator side during an ongoing dispute strongly increases the risk that a third party will join the initiator at any point during a dispute, but this effect is only significant after one month into a dispute. However, a major power joining on the target side significantly increases the risk that a third party will join the target only relatively early in the dispute. The risk of a third party joining the target after a major power has joined the target is quite substantial, starting at 14,327 per cent and decreasing to 524 per cent compared to the risk of a third party joining the target without a major power joining the target within the first six months of a MID. Additionally, within the first six months of a MID, the percentage increase in the risk of joining the target after a major power joined the target is always higher than the percentage increase in the risk of a third party joining the initiator after a major power joined the initiator. However, the percentage increase in the risk of joining the initiator following the joining by a major power is always higher than the risk of a third party joining the target following a major power joining the target after the first year of a MID, and increases as the MID persists.

In sum, we find evidence of both balancing and bandwagoning. These results suggest that previous major power participation on the side of the initiator significantly increases the risk of joining the initiator (bandwagoning) and previous major power participation on the side of the target increases the risk of joining the target (balancing). Moreover, these results suggest that we should observe balancing only relatively early during a MID, since third parties are less likely to balance as the MID persists, and that we should observe bandwagoning after the first month of a MID, since third parties are more likely to bandwagon as the MID persists. These results are consistent with our expectations and the empirical findings of Yamamoto and Bremer. ${ }^{135}$

\section{CONCLUSION}

While conflict expansion is a relatively rare event, conflicts that do expand tend to be deadlier than those that do not. A substantial amount of research has tried to identify the factors that influence a third party's decision to join an ongoing dispute. One frequently used approach to studying conflict expansion is the opportunity and willingness framework. In this article, we built upon this framework to examine how opportunity and willingness influence when third parties join ongoing disputes and which side they join in those disputes. This article makes three contributions to the existing research on conflict expansion.

First, our results provide new insight into the effect of variables highlighted in the conflict expansion literature that are important for third parties' decisions to join ongoing disputes. Specifically, our results show how these variables influence when and which side third parties join in ongoing disputes. Additionally, we have examined variables that have not been analysed in extant research (for example, rivalry) and variables that are often mentioned as being important but are not frequently analysed (for example, previous major power joining).

${ }^{134}$ In the Join Initiator model, the initial effect of previous major power joining is positive but not statistically significant in any of the samples except the politically relevant triads sample without World Wars I and II, in which the effect is negative but not statistically significant. The effect of previous major power joining increases over time in all of the samples, but is not statistically significant. In the Join Target model, the initial effect of previous major power joining is positive and statistically significant and significantly decreases over time in all four samples.

${ }^{135}$ Yamamoto and Bremer, 'Wider Wars and Restless Nights'. 
Secondly, our results contribute to some of the key debates in conflict research. In terms of the balancing versus bandwagoning debate, we find evidence for both sides, although which one is more likely depends on the length of a dispute and the mechanism that influences third parties' decisions. As a third party's capability contribution increases, there is a small chance that it will bandwagon within the first three months of a dispute but almost no chance afterwards. In contrast, there is a large chance that a third party will balance within the first two years of a dispute, but almost no chance afterwards. Thus in terms of a third party's capability contribution we found more evidence for balancing than bandwagoning, although both are less likely the longer a dispute lasts. The results for the previous major power joining variable suggest that we should observe balancing only relatively early in a dispute, since it is less likely to occur as a dispute persists. In contrast, we should only observe bandwagoning after the first month of a dispute, since it is more likely to occur as a dispute persists.

We found that alliance reliability varies by alliance type. Third parties that have a defence pact with the initiator are likely to join the initiator at any point during a dispute. In contrast, third parties that have a defence pact with the target are only likely to join the target in the first eight months of a dispute. However, within the first month of a dispute a third party that has a defence pact with the target is more likely to join the target than a third party that has a defence pact with the initiator is likely to join the initiator. Third parties that have an offence pact with a target are likely to fulfill their alliance commitments, but third parties that have an offence pact with the initiator are not. Finally, third parties that have a neutrality pact with an initiator are likely to join the initiator, but third parties that have a neutrality pact with a target are not likely to join the target.

In terms of regime type, we found that both democratic and autocratic third parties will join democratic and autocratic initiators, respectively, but not democratic and autocratic targets. If a third party and an initiator are both democratic, the risk of joining the initiator increases within the first six months of a dispute - after which it decreases. In contrast, if a third party and a target are both democratic, there is no statistically significant chance that the third party will join the target at any point during a dispute. Interestingly, we observed a similar pattern for autocratic third parties, which are likely to join an autocratic initiator early in a dispute but are not likely to join an autocratic target at any point during a dispute. These findings suggest that democratic and autocratic third parties behave similarly in terms of when and which side they join during ongoing disputes.

Thirdly, our results demonstrate the importance of distinguishing between the decision to join the initiator of a dispute and the decision to join the target - and that doing so provides new insights into conflict expansion. There were substantial differences in variables' effects on the risk of joining between the pooled model and the risk-specific models. For some variables, the risk of joining is higher in one of the risk-specific models than the pooled model. For example, the effect of capability on the risk of joining is higher in the joining target model than in the pooled model. In other cases, the effect a variable has on the risk of joining in one of the risk-specific models is statistically significant but the effect is not statistically significant in the pooled model. For example, the effect of offence pacts on the risk of joining is statistically significant for joining the target, but is not statistically significant when we pool the risks. In addition, by distinguishing between joining the initiator and joining the target we uncovered several interesting results. As mentioned above, the risk of joining increases when a third party 
and an initiator are both democracies, but there is no significant relationship for the risk of joining when a third party and the target are both democracies. If we relied upon the results from the pooled model, we would not be able to distinguish these effects.

There are a number of additional avenues for future research. First, we have only considered military intervention by third parties. Since third-party participation can take many forms, ranging from arbitration and mediation to uses of military force, future research might consider when a third party decides to mediate, arbitrate or use military force - and on which side. Along these lines, future research might also consider the timing and side of other forms of intervention, such as diplomatic or economic. ${ }^{136}$ Secondly, we found evidence that the prior participation of a major power influences other third parties' decisions to join. Future research might consider how other characteristics of previous intervenors influences other third parties' decisions. For example, does the prior participation of a democracy influence the future participation of other democracies? Finally, we believe that more theoretical research is needed to account for the interdependent nature of third parties' decisions. If states that are considering starting a conflict base their decisions, in part, on whether or not third parties are expected to join (and on which side), third parties' decisions to join ongoing disputes are also likely based on whether or not other third parties will join in the future, when those third parties will join and on which side.

136 Corbetta, 'Determinants of Third Parties' Intervention and Alignment Choices'; Corbetta and Dixon, 'Danger Beyond Dyads'. 